Tiago Lamberti Negreira

Non-conventional Monetary Policy in Turkey:

A Synthetic Control Approach

Dissertação de Mestrado

Thesis presented to the Programa de Pós-graduação em Economia da PUC-Rio in partial fulfillment of the requirements for the degree of Mestre em Economia .

Advisor: Prof. Márcio Gomes Pinto Garcia 


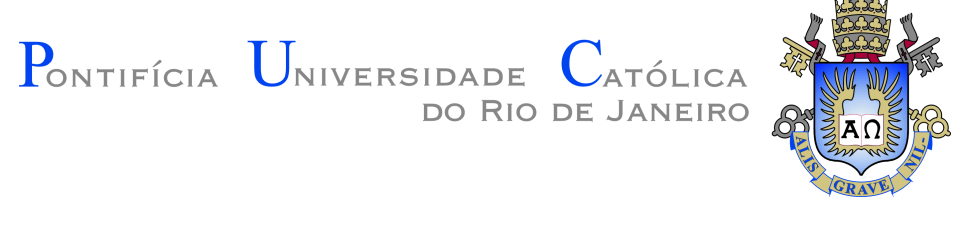

Tiago Lamberti Negreira

\title{
Non-conventional Monetary Policy in Turkey: A Synthetic Control Approach
}

Thesis presented to the Programa de Pós-graduação em Economia da PUC-Rio in partial fulfillment of the requirements for the degree of Mestre em Economia . Approved by the undersigned Examination Committee.

\author{
Prof. Márcio Gomes Pinto Garcia \\ Advisor \\ Departamento de Economia - PUC-Rio
}

Prof. Marcelo Cunha Medeiros Departamento de Economia - PUC-Rio

Prof. Luciano Vereda Oliveira Universidade Federal Fluminense - UFF

Centro de Tecnologia MineralCETEM/MCTI Rio de Janeiro, September the 26th, 2018 
All rights reserved.

Tiago Lamberti Negreira

B.A., Economics, Escola de Economia de Sao Paulo (FGV/EESP), 2015

Bibliographic data

Negreira, Tiago Lamberti

Non-conventional Monetary Policy in Turkey: A Synthetic Control Approach / Tiago Lamberti Negreira; advisor: Márcio Gomes Pinto Garcia. - Rio de janeiro: PUC-Rio, Departamento de Economia , 2018.

v., 59 f: il. color. ; $30 \mathrm{~cm}$

Dissertação (mestrado) - Pontifícia Universidade Católica do Rio de Janeiro, Departamento de Economia .

Inclui bibliografia

1. Economia - Teses. 2. Política Monetária;. 3. Finanças Internacionais;. 4. Instrumentos de Política Monetária;. 5. Políticas Macro-prudenciais;. 6. Controle Sintético;. 7. Turquia.. I. Garcia, Márcio Gomes Pinto. II. Pontifícia Universidade Católica do Rio de Janeiro . Departamento de Economia . III. Título. 
To my parents, Antonio and Cecilia, for their unconditional support. 


\section{Acknowledgments}

Firstly, I would like to express my candid gratitude to my advisor Prof. Márcio Garcia for the continuous support, patience and motivation, which helped me in all the time of research and writing of this work.

My sincere thanks also go to my family and friends, without which I would never make it this far.

I am thankful to the Conselho Nacional de Desenvolvimento Científico e Tecnológico - Brasil (CNPq), who has financed part of this this study. 


\section{Abstract}

Negreira, Tiago Lamberti; Garcia, Márcio Gomes Pinto (Advisor). Non-conventional Monetary Policy in Turkey: A Synthetic Control Approach. Rio de Janeiro, 2018. 59p. Dissertação de Mestrado - Departamento de Economia , Pontifícia Universidade Católica do Rio de Janeiro .

Do alternative monetary policy frameworks actually work? After the financial crisis and especially in late 2010, Turkey faced a conjecture of high volatility in international capital flows and deteriorating current account. The Central Bank of Turkey decided, then, to innovate the way it executes monetary policy, by introducing a new set of instruments and focusing on credit and exchange rate channels. This paper is a comparative case study that evaluates the effectiveness and impact of Turkey's change in policy framework on its main monetary variables. We apply two different synthetic control methods. Our estimates suggest inflation and exchange rate were not considerably affected. Although there was an initial deviation towards desirable directions, the effects dissipated after one year. On the other hand, domestic credit seem to have presented a stabilization path.

\section{Keywords}

Monetary Policy; International Finance; Monetary Policy Instruments; Macroprudential Policy; Synthetic Control; Turkey. 


\section{Resumo}

Negreira, Tiago Lamberti; Garcia, Márcio Gomes Pinto. Política Monetária Não-convencional na Turquia: Uma Abordagem em Controle Sintético. Rio de Janeiro, 2018. 59p. Dissertação de Mestrado - Departamento de Economia , Pontifícia Universidade Católica do Rio de Janeiro .

Políticas monetárias alternativas realmente funcionam? Depois da crise financeira e, especialmente, a partir de 2010, a Turquia enfrentou uma conjuntura de alta volatilidade nos fluxos de capital internacional e de deterioração na conta corrente. O Banco Cenral da Turquia decidiu, então, inovar sua maneira de executar a política monetária, introduzindo um novo conjunto de instrumentos e focando nos canais de crédito e câmbio. Este trabalho é um estudo de caso comparativo que avalia a eficácia e o impacto da nova estrutura de política da Turquia sobre suas principais variáveis monetárias. Nós aplicamos dois métodos de controle sintético. Nossas estimações sugerem que inflação e taxa de câmbio não foram consideravelmente afetadas. Apesar de um desvio inicial nas direções desejadas, os efeitos de dissiparam no prazo de um ano. Por outro lado, crédito doméstico parece ter entrado em uma trajetória de estabilização.

\section{Palavras-chave}

Política Monetária; Finanças Internacionais; Instrumentos de Política Monetária; Políticas Macro-prudenciais; Controle Sintético; Turquia. 


\section{Table of contents}

$\begin{array}{ll}\text { List of figures } & 9\end{array}$

$\begin{array}{ll}\text { List of tables } & 11\end{array}$

1 Introduction $\quad 12$

2 Related Literature $\quad 15$

3 The CBRT Policy 18

4 Methodology $\quad 21$

4.0.1 Synthetic Control Method (SCM) 21

4.0.2 Artificial Counterfactual (ArCo) 23

5 Data 25

$\begin{array}{lll}6 & \text { Results } & 28\end{array}$

6.0.1 Baseline Specification 28

6.0.1.1 CPI 28

6.0.1.2 Exchange Rate $\quad 30$

6.0.1.3 Credit 33

6.0.2 Alternative Specifications 34

6.0.2.1 CPI $\quad 35$

6.0.2.2 Exchange Rate 37

6.0.2.3 Credit 38

6.0.3 Artificial Counterfactual 40

7 Conclusions $\quad 44$

8 Bibliography $\quad 45$

$\begin{array}{ll}\text { A Appendix } & 47\end{array}$

$\begin{array}{ll}\text { A.1 The CBRT Policy } & 47\end{array}$

A.2 Data 48

A.3 Synthetic Control Estimates $\quad 51$

A.4 ArCo Estimates $\quad 57$ 


\section{List of figures}

Figure 3.1 Turkey Cuurent Account Defict. Source: Bloomberg 18

Figure 3.2 CBRT Policy Mix. Source: CBRT 20

Figure 5.1 Inflation and Exchange Rate in Turkey. Source: Bloomberg 26

(a) CPI, YoY 26

(b) Nominal Exchange Rate 26

Figure 5.2 Credit and Production in Turkey. Source: Bloomberg and

IMF 26

(a) Domestic Credit 26

(b) Industrial Production Index $\quad 26$

Figure 6.1 Synthetic Control for CPI 30

Figure 6.2 CPI Effects 30

Figure 6.3 Synthetic Control for Exchange Rate 32

Figure 6.4 Turkish Lira's soft-landing 32

Figure 6.5 Exchange Rate Effects. Note: The values give the percentage point difference between observed and potential accumulated depreciation of the Lira since September $2010 \quad 33$

Figure 6.6 Synthetic Control for Domestic Credit Growth 34

Figure 6.7 Domestic Credit Effects. Notes: The values give the percentage point difference between observed and potential growth of credit since September 2010

Figure 6.8 Synthetic Control with Level Specification for CPI 35

Figure 6.9 CPI Effects with Level Specification 36

Figure 6.10 Synthetic Control with Outcome Specification for CPI 36

Figure 6.11 CPI Effects with Outcome Specification 36

Figure 6.12 Synthetic Control with Level Specification for Exchange Rate

Figure 6.14 Synthetic Control with Outcome Specification for Exchange Rate 38

Figure 6.15 Exchange Rate Effects with Outcome Specification 38

Figure 6.16 Synthetic Control with Level Specification for Credit 39

Figure 6.17 Credit Effects with Level Specification 39

Figure 6.18 Synthetic Control with Outcome Specification for Credit 39

Figure 6.19 Credit Effects with Outcome Specification 40

Figure 6.20 ArCo for CPI 41

Figure 6.21 ArCo for Exchange Rate 41

Figure 6.22 ArCo for Domestic Credit 42

Figure 6.23 ArCo for Domestic Credit with alternative data 43 
Figure A.1 Supply and Demand for Funding in the CBRT New Policy Mix. Notes: The central bank chooses the amount of funding to supply in one-week repo auctions. If it is less than the liquidity necessity from banks, then the funding rate becomes the $\mathrm{O} / \mathrm{N}$ lending rate. The average funding rate of the central bank is the weighted average of both operations (shaded area in the graphic).

Figure A.2 Trade Balance in Turkey 48

Figure A.3 CPI for all controls (\%) 48

Figure A.4 Exchange Rate in all controls (level) 49

Figure A.5 Exchange Rate in all controls (variation) 49

Figure A.6 Credit growth in all controls (\%) 50

Figure A.7 $\quad$ First difference of credit growth in all controls (p.p.) 50

Figure A.8 p-values estimated for each period in CPI estimations, for each specification. Notes: the p-value is calculated as the proportion of placebo units who have not yield an effect as large as the treated has.
(a) Baseline
(b) Level
(c) Outcome

Figure A.9 p-values estimated for each period in exchange rate estimations, for each specification. Notes: the p-value is calculated as the proportion of placebo units who have not yield an effect as large as the treated has.
(a) Baseline
(b) Level
(c) Outcome

Figure A.10 p-values estimated for each period in credit estimations, for each specification. Notes: the p-value is calculated as the proportion of placebo units who have not yield an effect as large as the treated has.

(a) Baseline $\quad 56$

(b) Level 56

(c) Outcome 56

Figure A.11 ArCo raw estimation for Exchange Rate (log-difference) $\quad 57$

Figure A.12 ArCo raw estimations for Credit (first difference of growth rate)

Figure A.13 ArCo residuals $\quad 58$

Figure A.14 ArCo for CPI with alternative data $\quad 59$

Figure A.15 ArCo for exchange rate with alternative data 59 


\section{List of tables}

Table 5.1 Sample statistics in the 24 months prior to the CBRT policy 27

Table 5.2 Sample statistics in the 24 month following the CBRT $\begin{array}{ll}\text { policy } & 27\end{array}$

Table A.1 Estimated weights for CPI with the SCM 51

Table A.2 Estimated weights for Exchange Rate with the SCM 52

Table A.3 Estimated weights for Domestic Credit with the SCM 53

Table A.4 Synthetic Control's analogous $R^{2}$ and joint p-values $\quad 56$

Table A.5 ArCo p-values. Notes: p-values are calculated by the 'ArCo' R package $\quad 57$

Table A.6 Estimated average effect and Interval Confidence for ArCo 57

Table A.7 ArCo p-values for alternative credit data. Notes: p-values are calculated by the 'ArCo' R package 59

Table A.8 Estimated average effect and Interval Confidence for ArCo with alternative credit data 


\section{Introduction}

In a context of questioning what was, until the late 2000s, taken as consensus in monetary policy, macroprudential measures and non-conventional set of instruments have come to the spotlight. Central banks in developed markets promoted an aggressive liquidity strategy, in order to protect the financial system and stimulate activity. As a consequence, international markets were flooded with capital (Fratzscher et al. (2018), Bruno and Shin (2015)). Emerging markets, who were initially trying to solve a liquidity shortage, had to react to the opposite phenomenon afterward. The arrangements conceived with this background, although creative, should be analyzed very carefully, in the sense of whether they are able to promote financial stability without considerable costs to the central bank's primary function: price stability. Some studies like Jinjarak et al. (2013), Claessens et al. (2013) derive mixed effects from macroprudential policies. Others, like Chamon et al. (2017) aim at measuring central banks' power to influence capital flows. Considering the plethora of available tools, there is still plenty room for scrutiny of such innovations.

More specifically, it is reasonable to ask if a new monetary policy stance is capable to promote both price stability and financial stability. That is, if a central bank using alternative instruments can influence determinant variables in the financial system and, at the same time, assure inflation will follow a tenable path. In this paper, we evaluate short and mid-term effects of Turkey's monetary policy shift on three key variables. The first one being inflation, as expected for an inflation targeting central bank. The other two being exchange rate and domestic credit, taken as the main transmission channels and communication variables by the Central Bank of the Republic of Turkey (CBRT).

For this analysis, we use a synthetic control approach, described by Abadie et al. (2010) and Abadie et al. (2015). The goal is to estimate how the outcome variables would have behaved had Turkey not implemented the new set of instruments. In addition, we construct another artificial counterfactual using the method proposed by Carvalho et al. (2016). Previous works explored the impact of macro-prudential policies on central bank efficiency. To the best of our knowledge, ours is the first to apply the aforementioned methods 
in this context. Furthermore, we contemplate in our analysis some recent contributions made to the synthetic control literature.

As liquidity fluctuates in global markets, emerging economies try to adapt and respond to simultaneous unpredictable phenomena. Not by chance, the case of Turkey is of great interest when we discuss alternatives to central bankers, who may be looking for instruments that are more sensitive to these uncertainties. The new framework announced by the Central Bank of Turkey by the end of 2010 is rather distinct and might provide some insight to the issue. It involves an interest rate corridor and a daily-based liquidity management instrument, which in practice are derived from existing tools. Besides its particularities, its implementation fits properly in a comparative case study approach, when we need control units to acknowledge the real effect of the intervention.

In the synthetic control method, we construct a comparison unit by attributing different weights to available control countries, based on the preintervention period. The artificial counterfactual suggested by Carvalho et al. (2016) is arguably similar and it works in a two-step approach: the first is estimating a model using the data previous to the event of interest, and the second is estimating the average intervention effect on the treated unit. Their model allows for multiple variables analysis, as well as a defined inference procedure. Regarding inference for the synthetic control, Abadie et al. (2015) present a strategy, but recent papers in the field point out some precautions to take.

Our main findings weakly suggest that, at first, the new monetary policy framework was able to achieve the desired soft-lending in the economy. By pressing credit growth down, lowering inflation and, at the same time, depreciating the Turkish Lira, the central bank responded well to adversities in 2011. However, these positive effects seem to fade over time, as price stability overcome the financial stability goal. We were able to apply a reasonable inference procedure, thanks to the advances made in the literature, like in Kaul et al. (2015) and Ferman et al. (2018). The overall effect on each outcome variable, according to the synthetic control method is almost never significant. When applying the Artificial Counterfactual method, we obtain very similar results for variables taken separately, with the exception of credit, which has possibly diverted to stabilization. Still, using a well-defined test we obtain joint significance for effects on all variables. Our results contribute to the debate on alternative monetary policies and macro-prudential practices when it comes to central bankers trying to shield the domestic financial system from foreign instability. Policymakers may have the flexibility required for integrated 
capital markets, but they are bounded by good domestic fundamentals and well-designed instruments. We also incite the use of data-driven methods for comparative case studies in macroeconomics, such as Billmeier and Nannicini (2013) and Jinjarak et al. (2013). We encourage not only the synthetic control method but also the ArCo, which is very appropriate for large samples and multiple outcome analysis as ours. Further studies on the case of Turkey could focus on financial market and high-frequency data, as carried out by Chamon et al. (2017) in Brazil, since we focus mainly on monetary policy traditional features.

The remainder of the paper is organized as follows. Section 2 presents a brief review of the related literature. Section 3 explains the fundamentals of the new policy in Turkey. In Section 4 we outline the methodologies used. Data are described in section 5. Section 6 displays the results of our estimations. In Section 7 we expose our conclusions. Some Tables and Figures are relegated to the Appendix. 


\section{2}

\section{Related Literature}

This paper is included in the recent but extensive synthetic control method (SCM) literature. The series of seminal papers Abadie and Gardeazabal (2003), Abadie et al. (2010) and Abadie et al. (2015) set the groundwork for a wide range of comparative case studies, due to the model's relative simplicity and suitability for small data sample. Athey and Imbens (2017) give praise to the method, considering it as one of the most important innovations in policy evaluation literature. The papers also paved the way for theoretical and statistical developments regarding construction of counterfactuals. Klößner and Pfeifer (2015) proposed a generalized method, that comprises time series and multiple outcome variables, and used it to evaluate the car scrappage programs in Europe. Another modeling discussion comes from Ferman and Pinto (2018), that revisited the methodology and proved the estimator can be asymptotically biased. The authors prescribe care in interpreting assumptions and suggest a modification to ameliorate the risk of bias.

There are papers that address the choice of specification in SCM. Ferman et al. (2018) criticized its vulnerability to specification searching when researchers choose variables, controls and outcome lags. They recommend caution, multiple analyses, and alternative inference procedures. Kaul et al. (2015) proved that control variables are unimportant when using all lags of the outcome variable as predictors. The implications of both papers will be revisited in Sections 4 and 6. Regarding inference in SCM, Ferman and Pinto (2017) examined the graphic analysis with placebos and concluded it might be misleading, in terms of yielding false significant effects. The authors also pointed out problems in test sizes proposed by Abadie et al. (2015). Firpo and Possebom (2017) echoed the test problems and, in addition, suggested the construction of a confidence set for more reliable inference. As mentioned before, we will take some of these developments into account, so that we contribute to the advance in empirical comparative case literature.

Accordingly, there is a vast list of works when it comes to the application of the SCM. It is very common in the literature to use annual data, such as Sanso-Navarro (2011) and Pinotti (2015). Whilst the former wanted to value foreign direct investments differences after the non-entry of the United 
Kingdom in the euro area, the latter measured how the presence of mafia affected income and crime in Italy. Our study also checks for variation in specific country aggregate variables, with the advantage of monthly data and a well-known period of intervention. Billmeier and Nannicini (2013), on the other hand, implemented the SCM in a worldwide exercise. With data covering forty years, the paper stands for non-negative increments in income caused by economic liberalization. Although they carry out the placebo estimations for validation, the nuances around the definition of liberalization, the period choice and the controls inclusion make it difficult to draw conclusions. The singularity of Turkey's new monetary policy stance, however, alleviates those uncertainties.

When it comes to applying traditional SCM, the research in Jinjarak et al. (2013) is the most similar to our work. It constructs a synthetic Brazil and tests for five different policy announcements of capital controls. Besides dealing with prudential policies, the authors run their estimates with weekly data and specific capital flow indicators. This approach would be very interesting for the case of Turkey, but here we focus on price stability and financial stability representative variables, as conceived by the CBRT.

It is important to note that we are not only applying the SCM, but also the Artificial Counterfactual (ArCo) method, developed by Carvalho et al. (2016). So we will be able to get more robust results, considering several advantages provided by this estimator. It will be useful as well to compare different methods and check the suitability of our data for each one. Because we apply both SCM and ArCo, the work presented by Chamon et al. (2017) is, as far as we know, the most similar in terms of methodology. The authors explore the interventions on foreign exchange by the Central Bank of Brazil.

Although the new policy framework in Turkey does not translate into an active regulation of the financial system, it is reasonable to argue that they are part of an international trend towards macro-prudential policies. The purposes guiding the CBRT are essentially the same: decrease in credit growth, protection from sudden stops and healthy banks' balance sheet composition. With that in mind, our study also contributes to the evaluation of such policies, in the context of post-crisis financial stability.

Many papers seek to verify the effectiveness of such regulations and to identify whether they offer limitations to monetary policymakers. Beau et al. (2012) concluded, through a DSGE model, that a macro-prudential authority committed to hinder credit does not affect price stability. Benigno et al. (2013) emphasized the importance of ex-post responses, stating that crisis administration is more effective and less costly to welfare, while Claessens et al. 
(2013) advocated for rules that build up buffers, like required reserves. The last two are relevant to our analysis because Turkey implemented different required reserves ratios according to maturity, and a framework that was designed to better respond to volatile movements of liquidity. Connected to the studies above, there is also a part of the literature regarding the effects of quantitative easing on emerging economies. Lavigne et al. (2014) and Fratzscher et al. (2018) provide evidence that the movement of capital from advanced to developing economies leads to increase in asset prices and currency appreciation, as well as to increase in pro-cyclicality of flows. This last information supports the CBRT's intentions to soften portfolio flows. More specifically on the channels of monetary policy and capital flows, Jiménez et al. (2012) and Bruno and Shin (2015) agree that banks play an especial role in transmission, due to the availability of credit. In that sense, it is reasonable to investigate how the changes in funding markets by the central bank in Turkey affected credit availability, in the context of volatile access to international capital.

Finally, this paper correlates to specific studies in Turkey. Kara (2013) provided great insight and elucidation about the new framework, motivating a deeper understanding of its effects. We hope to address part of the questions aroused by the author. Binici et al. (2016) also discussed the aspects of CBRT shift in monetary policy, but with interest on the transmission mechanisms from the multiple policy rates to loans rates. The authors conclude that the effective interest rate, rather than the announced policy rate, is the one ruling banks' decisions. Our study, then, try to shed light on different impacts, focusing on three main variables: inflation, exchange rate and credit, in order to evaluate the capability to achieve their ultimate goals: price and financial stability. 


\section{3}

\section{The CBRT Policy}

During the first two years of global crisis, The Central Bank of Turkey (CBRT) implemented different measures to protect the country from an initial liquidity shortage in the financial system. However, as each leading central bank aimed for recovery in investments and activity to its own country, emerging markets became exposed, in fact, to an excess of liquidity.

After reassessing the monetary policy stance applied to the context of financial crisis, the CBRT signaled at the end of 2009 it could revoke or at least soften some of the main arrangements established since November 2008. These signs were confirmed by a press release issued in April 2010, named the "Exit Strategy". The central bank announced it would start a process of normalizing the monetary policy framework back to the pre-crisis status. However, through different communication reports ${ }^{1}$, it became increasingly explicit the desire for more flexible instruments that, in turn, would enable more responsive policies focused on financial stability. Thus, in the same document, the central bank also highlighted that a new framework would be put into practice, conditional on the rise in excess of funding in capital markets for the next months. To illustrate the intensity of capital inflows, Figure 3.1 depicts the current account deterioration in 2010.

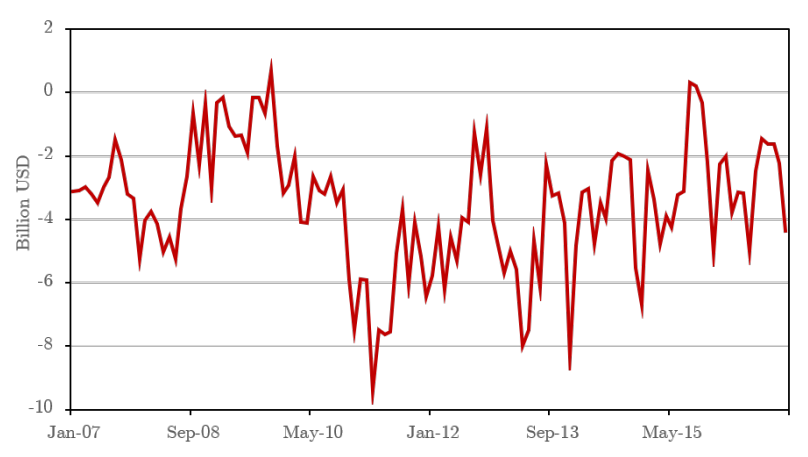

Figure 3.1: Turkey Cuurent Account Defict. Source: Bloomberg

Finally, in October 2010, the CBRT issued a press release determining the end of the intermediary function of the CBRT in the foreign exchange deposit market. Additionally, it ended 3-month repo funding auctions. Thereby, the

${ }^{1}$ Monthly press releases, quarterly Inflation Reports and annual Monetary Policy Reports 
announced framework could be effectively put into practice. It was a new set of instruments, along with new measures for traditional ones. The new policy mix presented by the CBRT consisted of four main ingredients: a corridor overnight interest rate, a weekly auction rate, reserves requirements, and a liquidity management policy. Although most of these instruments were already somewhat included in CBRT's scope, it was only from the end of 2010 and more assertively during the 2011-2014 period that they became the explicit official policy instruments.

Each month, the Monetary Policy Committee would meet and determine the three basic short-term interest rates: the overnight lending and borrowing rates, which formed the interest rate corridor, and the weekly repo rate. The latter was not necessarily set to the middle of the interval so that asymmetry in the corridor would be used as an instrument itself. While the borrowing rate dictated the amount of daily interest paid to deposits in CBRT, the other two represented the lending rates of the central bank.

As opposed to a conventional inflation targeting framework, in which the policy rate usually matches the average funding rate by the central bank, the non-conventional set of multiple rates allows detachment between them on a daily basis. This was achieved through liquidity management operations. The CBRT could adjust the supply of funds in one-week repo auctions so that the rate paid by banks could be either the one-week repo rate or the upper bound in the interest rate corridor ${ }^{2}$. The average cost of funding by the CBRT, then, was the weighted average of the two different rates, with the weights being determined by the amount of funds provided.

By turning uncertainty about interest rates into an instrument, the central bank could prompt private banks to take the upper limit of the corridor as a reference. As a consequence, the loan-deposit spread became related to this margin. The width of the corridor was also useful to change exchange volatility according to capital flows.

Finally, in response to the liquidity shortage after the crisis, required reserves were basically abandoned by the CBRT. Nevertheless, the excess of foreign capital led to maturity mismatch in private banks. To tackle the problem and to add a complementary instrument, they not only increased required reserves but also implemented different rates according to the maturity composition of deposits. In that way, the central bank could balance variations in interest rates with reserves counterparts. Figure 3.2 shows how monetary instruments behaved during the period of our analysis. It is possible to see when the new framework started to function and how average cost of funding

\footnotetext{
${ }^{2}$ See the Appendix for an illustration of the fund market
} 
deviated from the basic policy rate.

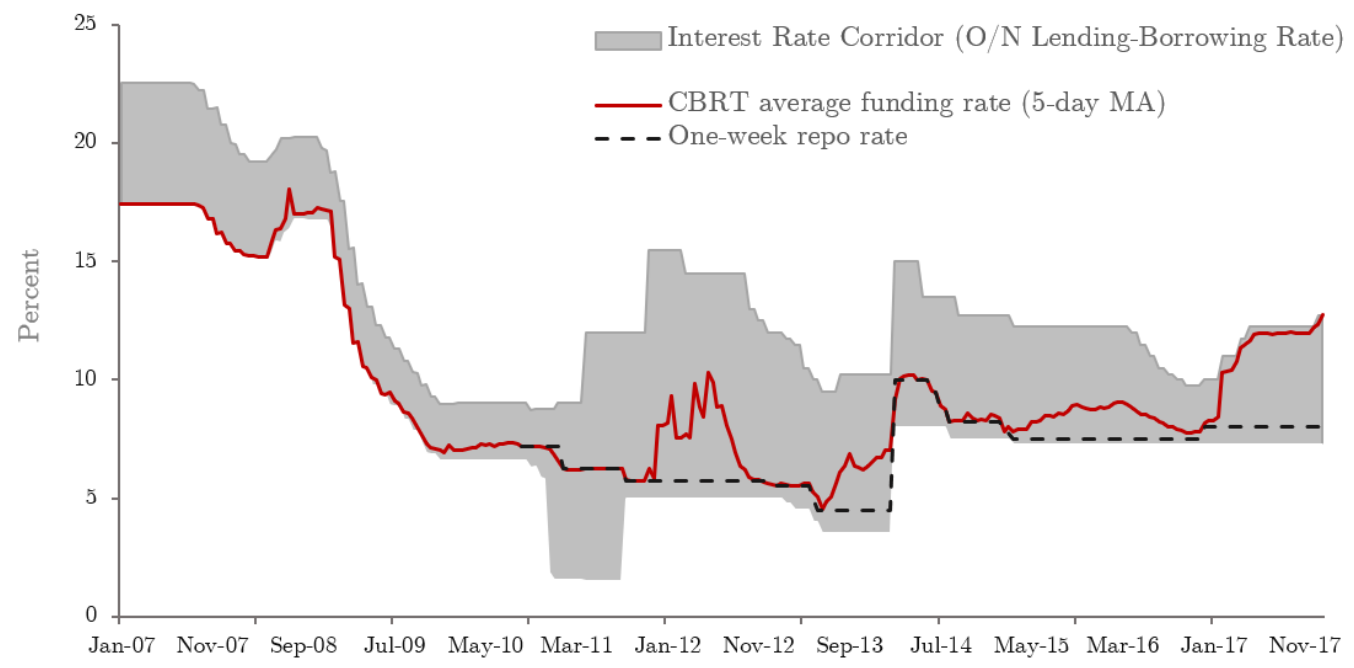

Figure 3.2: CBRT Policy Mix. Source: CBRT 


\section{Methodology}

A comparative case study deals with a unit exposed to an intervention, in our case, a country experienced a monetary policy shift, while other units remained unaffected. Suppose that we observe $J+1$ units, or countries, meaning $J$ potential controls and one exposed-to-intervention unit.

Let $Y_{i t}^{N}$ be the variables of interest, i.e. inflation, exchange rates and domestic credit, for country $i$ at time $t$ in the absence of the new policy, with $i=1, \ldots, J+1$ and $t=1, \ldots, T$. Now let $Y_{i t}^{I}$ be the outcome the would be observed if country $i$ was exposed to the intervention and $t$ is after its implementation period $T_{0}$, with $1 \leq T_{0}<T$. We assume the outcome is not affected by the policy before $T_{0}$, but continues uninterruptedly affected from $T_{0}+1$ on. So, for $t \in\left\{1, \ldots, T_{0}\right\}$ and all $i \in\{1, \ldots, J+1\}$, we have that $Y_{i t}^{I}=Y_{i t}^{N}$.

The effect of the new policy can be defined as $\alpha_{i t}=Y_{i t}^{I}-Y_{i t}^{N}$. Assuming, without loss of generality, that Turkey is the first country, we seek to estimate $\left(\alpha_{1 T_{0}}, \ldots, \alpha_{1 T}\right)$. For $t>T_{0}$, we have $\alpha_{1 t}=Y_{1 t}^{I}-Y_{1 t}^{N}=Y_{1 t}-Y_{1 t}^{N}$. Our main purpose is to test the null hypothesis $\alpha_{1 t}=0$, that is, if the intervention has any effect after all. Hence, we only need to estimate $Y_{1 t}^{N}$. Next, we define an approximating model for $Y_{1 t}$ that can be a general measurable mapping. In our study, we will stick to the model discussed by Carvalho et al. (2016), which is the approximation to the conditional mean $m\left(Z_{t}\right)=\mathbb{E}\left(Y_{t}^{N} \mid Z_{t}\right)$. The authors also propose to use a parametric linear model to obtain $m\left(Z_{t}\right)$. By doing so, we obtain a linear equation for each variable of interest:

$$
Y_{1 t}^{N}=\boldsymbol{\theta} \boldsymbol{Z}_{t}+\varepsilon_{1 t}
$$

where $\boldsymbol{Z}_{t}$ is a $(r \times 1)$ vector of observed covariates in the unitreated units, $\boldsymbol{\theta}_{t}$ is a $(1 \times r)$ vector of unknown parameters and $\varepsilon_{i t}$ is a term o error.

\subsection{1}

\section{Synthetic Control Method (SCM)}

The methods we are using for this analysis propose different approaches to deal with the model above. Abadie et al. (2010) works with a simple vector of weights. Let $\boldsymbol{W}=\left(w_{2}, \ldots, w_{J+1}\right)^{\prime}$ be a $(J \times 1)$ vector of weights such that $w_{j} \geq 0$ for $j=2, \ldots, J+1$ and $\sum_{j=2}^{J+1} w_{j}=1$. Each $\boldsymbol{W}$ will provide a weighted 
average of control countries, so we call it a potential synthetic control. The authors' main result is that if we are able to find one $\boldsymbol{W}^{*}$ that depicts the outcome variables (and observed covariates) of the affected country previous to the intervention, then we obtain an estimator for the policy effect $\alpha_{1 t}{ }^{1}$ :

$$
\hat{\alpha}_{1 t}=Y_{1 t}-\sum_{j=2}^{J+1} w_{j}^{*} Y_{j t} \quad \text { for } \quad t \geq T_{0}+1
$$

To implement this method, we first define $\boldsymbol{X}_{1}$ as a vector of preintervention variables (outcome $Y_{1}$ and observable $\boldsymbol{Z}_{1}$ ) from the exposed country, and a matrix $\boldsymbol{X}_{0}$ containing the same characteristics for the unaffected countries. We choose $\boldsymbol{W}^{*}$ that minimizes the distance $\left\|\boldsymbol{X}_{1}-\boldsymbol{X}_{0} \boldsymbol{W}\right\|$. Then, we employ the minimization to the following measure:

$$
\sqrt{\left(\boldsymbol{X}_{1}-\boldsymbol{X}_{0} \boldsymbol{W}\right)^{\prime} \boldsymbol{V}\left(\boldsymbol{X}_{1}-\boldsymbol{X}_{0} \boldsymbol{W}\right)}
$$

where $\boldsymbol{V}$ is a symmetric and positive semi-definite matrix, which minimizes the squared prediction error of the outcome variable for periods before the new policy.

Inference for the synthetic control approach is restricted. Abadie et al. (2010) proposed a series of falsification tests, which the authors call "placebo tests". The procedure is to apply the method to every potential control in the sample. If we observe large effects on the outcome variable from other units, maybe the intervention is not as significant as expected. In Abadie et al. (2015) they use this concept to introduce a p-value. However, since our policy is not randomized, the interpretation of the p-value is slightly different from the usual. It the can be seen as the probability of obtaining an estimate at least as large as the one obtained for the treated unit when the intervention is reassigned at random in the data set. We can calculate p-values for a specific period or for the whole sample (joint p-value).

Due to the extensive applicability of synthetic control, there have been advances in the literature, especially concerning inference and research prescription. Ferman and Pinto (2018) revisited the framework and argue that, under some conditions, the SCM estimator is asymptotically biased, so it demands caution. One of their advice is to consider detrending the data. They also highlight that the properties of the SC are conditional on a good pretreatment fit.

However, Ferman et al. (2018) state that, because there is not a consensus on estimation report in SC literature, researchers are subject to specification searching problem. Furthermore, they prove that researchers should only

\footnotetext{
${ }^{1}$ See Appendix B in Abadie et al. (2010) for proof, under regular conditions.
} 
consider specifications that use an infinitely large number of pre-intervention outcome values when the pre-intervention period gets large. Another suggestion is to report different specifications, which we will do later in this paper. Still regarding the specification choice, Kaul et al. (2015) prove that whenever one uses all outcome lags as predictors, covariates become redundant, so we will make that distinction. On top of that, Abadie et al. (2015) argues in favor of executing a cross validation procedure when estimating the optimal weights. Briefly, it consists of using part of the untreated sample to calculate the importance of each variable (training period) and then using the results to minimize quadratic errors in the other part of untreated sample (validation period).

As for the placebo tests, Ferman and Pinto (2017) explain that they can be misleading and present size distortions. Among the reasons is the exclusion of potential controls with large variations. Thus, we try to avoid over selecting and interpret graphs with parsimony, taking p-values into account. Finally, Firpo and Possebom (2017) propose a different inference method, by changing the quadratic error statistic, inverting it and providing a confidence set. They also propose a multiple variable adjustment. Although these innovations are very powerful and suitable for our study, we are not applying them.

\subsection{2 \\ Artificial Counterfactual (ArCo)}

We now present a brief look at Carvalho et al. (2016). This method differs from the SCM in what can be considered variable of interest and what can be part of $\boldsymbol{Z}_{t}$. Their arrangement allows for transformations in $Y_{1 t}$, like moments of higher orders, and also for simultaneous estimation with multiple variables of interest.

First, Carvalho et al. (2016) recommends us to collect all the untreated observable variables, including arbitrary lags so we construct $\boldsymbol{Z}_{\boldsymbol{t}}$ whose dimensions depends on the number of unaffected countries, number of variables and lags chosen. Then we have the model as presented above, for each of the variables of interest, where the term of error includes both the approximation error and the projection error. Finally, we have to estimate the vector of parameter $\theta$.

If the number of peers and/or the number of variables are too high, the number of parameters to be estimated can grow rapidly. To address this issue, Carvalho et al. (2016) argued that the dimension of $\boldsymbol{\theta}$ should depend on the size of the sample $T$ and, then, we should use shrinkage methods to estimate it. In particular, they propose an equation-by-equation LASSO estimation. 
We still have to characterize the Artificial Counterfactual estimator. A key assumption to recover the intervention effects is the independence between the variables from the donors pool and the intervention. It is quite reasonable to assume that is the case for Turkey's shift in monetary policy. We define $y_{t}$ the vector of $q$ variables of interest $Y_{1 t}$. We then need to estimate $\theta_{q, T_{1}}$, where $T_{1} \equiv T_{0}-1$, the period previous to the intervention. Therefore, if we define $\Delta_{T}$ as a measure of the average treatment effect, we have:

$$
\hat{\Delta_{T}}=\frac{1}{T-T_{0}+1} \sum_{t=T_{0}}^{T} \boldsymbol{y}_{t}-\left(\hat{\boldsymbol{\theta}}_{1, T_{1}}^{\prime} \boldsymbol{Z}_{1, t}, \ldots, \hat{\boldsymbol{\theta}}_{q, T_{1}}^{\prime} \boldsymbol{Z}_{q, t}\right)^{\prime},
$$

the Artificial Counterfactual estimator. Where $\hat{\boldsymbol{\theta}}_{j, T_{1}}$ is the LASSO estimator for the linear projection. Accordingly, the ArCo is a two-stage estimator: the first to estimate the model with the pre-intervention sample, and the second to compute the potential effects of the policy.

Carvalho et al. (2016) prove in the paper that, under a set of assumptions for compatibility, heterogeneity and regularity, the estimator above converges asymptotically to normality, which makes hypothesis testing straightforward. 


\section{Data}

The main objectives of the CBRT, in the new framework, is to achieve both price and financial stability. According to Kara (2013), the two intermediate variables that link the new instruments to the final goals in a more tangible way are exchange rate and credit. They were also important for communication, given the complexity of the new framework. So our analysis will focus on those three variables. The first is given by the usual monthly annualized Consumer Price Index (CPI) variation, the second is the monthly average nominal U.S. dollar nominal quotation and the third is domestic credit growth, calculated through year-over-year rate ${ }^{1}$. Figure 5.1 depicts CPI and exchange rate during the period of analysis.

Besides the outcome variables, we include two covariates: trade balance as a proportion of the GDP and the Industrial Production Index. The choice of variables for the synthetic control method is not well defined, as noted by Ferman et al. (2018). Our picks for the two variables is based on capturing measures of external exposure and economic activity, respectively. Figure 5.2 depicts the production index, as well as the credit variable. The trade balance graph is displayed in the Appendix (Figure A.2, although it is very similar to current account deficit shown in Figure 3.1.

The time span considered in this study starts in January 2007 and ends in December 2016, a total of 120 periods. According to the literature, the more pre-treatment observations, the better the estimates. However, it was not until 2006 that Turkey adopted an inflation targeting regime, so data before that period is volatile and the fact of having a different framework could interfere with the analysis.

We use monthly data, most of them obtained from the International Financial Statistics (IFS) reported by the International Monetary Fund. In addition, we used the CEIC Data platform (from the ISI Emerging Markets Group) to add more countries to the sample. Our database includes data from 33 countries beyond Turkey. We tried to comprehend emerging economies across the globe, as well as OCDE markets, adding up to 60 countries initially. Throughout our study, some of them were cut off due to data availability or bad

\footnotetext{
${ }^{1}$ Throughout the text we will refer "domestic credit" as the growth rate of domestic credit
} 
fitting in the estimations. It is worth noting that the SCM leads to a typical trade-off between countries, variables and periods. We prioritized the time span and control units, in order to avoid some of the reported size problems in inference. In Appendix C, it is possible to check graphs of our variables of interest for all countries in the period of analysis.

To generate more robust results we made some transformations in the variables: we applied the log difference to the exchange rate. For credit and trade we chose to apply simply the first difference, since we do not know their data generating process. We also used the percent change for the industrial index. Transformations are not only suggested but mandatory for the Artificial Counterfactual.

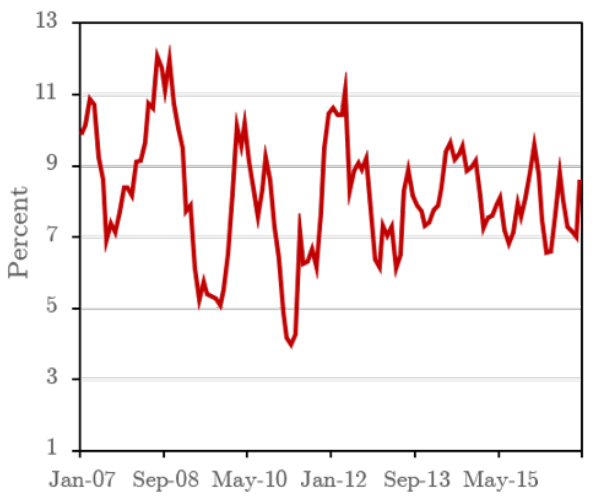

(a) CPI, YoY

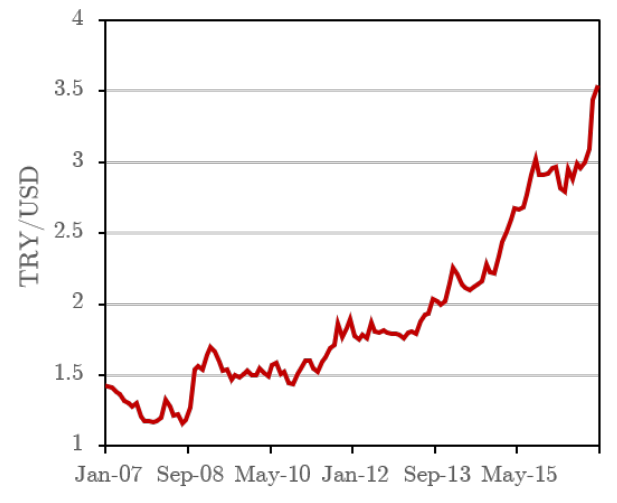

(b) Nominal Exchange Rate

Figure 5.1: Inflation and Exchange Rate in Turkey. Source: Bloomberg

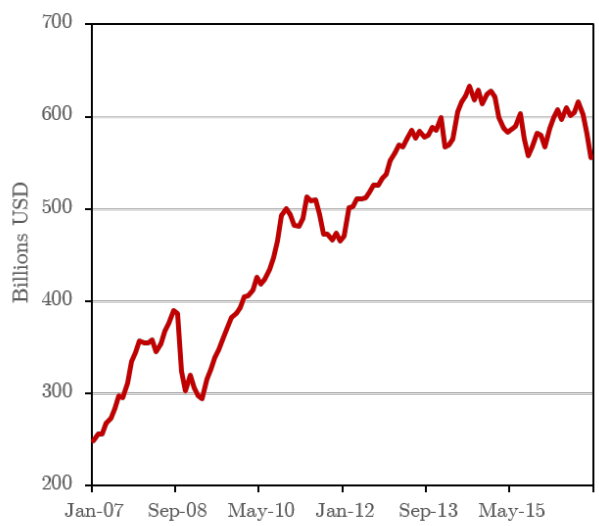

(a) Domestic Credit

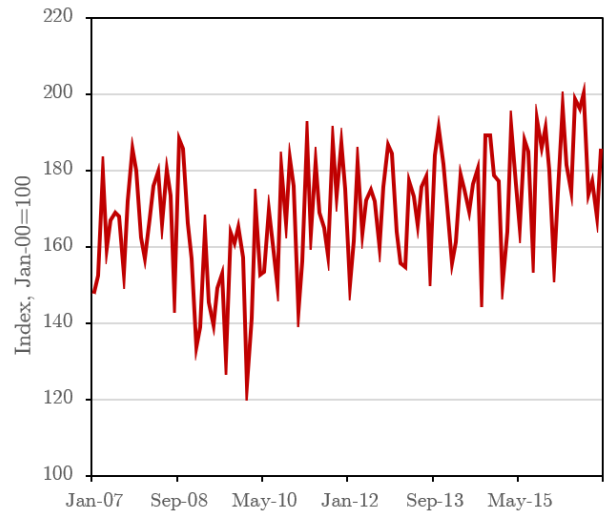

(b) Industrial Production Index

Figure 5.2: Credit and Production in Turkey. Source: Bloomberg and IMF 
If we can motivate the use of counterfactual methods for the case of Turkey, we can look at basic statistics from the data before and after the new policy. In tables 5.1 and 5.2 we present the calculated mean and variance of the three main variables 24 months before and after the policy change, respectively. Firstly, inflation do not seem to have expericned a break in its simple moments, while the percent change of the exchange rate, on average, went up but with less variation. Credit growth on the other hand, inverted direction from expansion to contraction and mutually recorded a drop in variance, which, at first glance, indicates the CBRT manged to achieve some degree of financial stability.

\begin{tabular}{lccc}
\hline \hline & CPI & Exchange rate & Domestic credit \\
\hline Mean & 0.0790 & 0.0060 & 0.0018 \\
Variance & 0.0004 & 0.0033 & 0.0072 \\
\hline
\end{tabular}

Table 5.1: Sample statistics in the 24 months prior to the CBRT policy

\begin{tabular}{lccc}
\hline \hline & CPI & Exchange rate & Domestic credit \\
\hline Mean & 0.0778 & 0.0085 & -0.0042 \\
Variance & 0.0005 & 0.0012 & 0.0016 \\
\hline
\end{tabular}

Table 5.2: Sample statistics in the 24 month following the CBRT policy 


\section{6 \\ Results}

As described in the methodology section, we will follow some recommendations when reporting the results. First, we will use a baseline specification for each of the three outcome variables. We chose the cross-validation estimation, using half of the pre-treatment outcome variable as predictor, which respects Abadie et al. (2015) and Ferman et al. (2018)'s piece of advice. Then, we will show two alternative specifications: one using the level data and the other using the whole pre-treatment outcome variable as the predictor. Inference will be displayed as described previously.

\subsection{1}

\section{Baseline Specification}

\subsubsection{1}

CPI

Figure 6.1 depicts the observed monthly inflation (CPI) and the synthetic inflation for Turkey during the period of analysis. The intervention date is October 2010, with the dashed vertical line indicating the period immediately prior to the announcement of the new policy framework.

The first thing to notice is the good fit of our estimations to the actual data in the pre-treatment sample, providing us with some confidence that the SC approach is suitable for our study. On the other hand, we use the formula proposed by Ferman et al. (2018) of a statistic analogous to the $R^{2}$, and the result is not substantial (0.5). The second visible information we get is the fast detachment between the variables right after the policy announcement. While the synthetic inflation hikes up above the two-digit level, the observed CPI drops to nearly 4 percent. The gap persists for about one year until it narrows by the beginning of 2012. After fluctuating similarly for another year, they separate again and stabilize at different levels.

Explaining the initial abrupt detachment is not trivial due to a series of simultaneous events. Before the new policy, Turkey was experiencing intense capital inflows. Using the new monetary tools, the CBRT widened the interest rate corridor downwards, in order to increase downside risks on overnight 
interest rates and, then, to discourage short-term capital inflows. At the same time, required reserves ratios were lifted, to avoid inflationary pressure. Thus, the most plausible explanation for the inflation decrease is via the credit channel. With banks more dependent on the central bank funding to meet their liquidity requirements and weakened foreign capital, domestic credit growth would slow down. As a consequence, inflation reduced, despite the Lira depreciation. We will check this conjecture later in the section. Furthermore, it is possible that the central bank was able to anchor expectations to the targeted inflation of $6.5 \%$ in 2010 and 5\% in 2011 (at least during the first half), which made realized inflation fall from the pre-announcement level of around $9 \%$.

The decrease in risk appetite and the rise of the debt crisis in the euro area in mid-2011 curbed capital inflows, so the CBRT adjusted interest rates to avoid a sudden stop. Figure 3.2 is useful to confirm those decisions. By the end of 2011, the crisis hit emerging markets and the domestic currency depreciated. Also, administered prices in Turkey hiked, therefore inflation increased quickly. The central bank implemented additional tightening by reducing funds in oneweek auctions. Anyway, the graph suggests inflation ended up reaching levels that it would have reached had it not been a new policy framework. On the other hand, it started to fall a few months before the estimated synthetic inflation.

The persistent deviation observed since 2013 may not be attributed to the new monetary policy instruments. Usually, in synthetic control analysis, it is expected that the intervention in question causes permanent shifts in the outcome variable, which is not our case. To illustrate that issue and start the inference procedure, Figire 6.2 presents the estimated placebo effects, i.e., the gap between the observed and the synthetic inflation for Turkey (dark red line) and every other control country (grey lines). Fortunately, this gap keeps swinging around the zero during the pre-intervention periods. As for the post-intervention period, the initial fall in CPI is clearly large relatively to possible effects in other economies. However, soon after, the effects seem to shuffle for a long period. From the end of 2013 onwards, the gap becomes increasingly positive and depart from the rest. Still, this inversion in effects is hardly related to the intervention, since this portion of the sample is a long time after the announcement and prediction errors can be misleading. Moving forward in inference, we can calculate p-values for separate time periods and for the joint sample. Graphs of time p-values are in the Appendix (Figure a), as well as Table A.4, presenting the $R^{2}$ and joint p-values for every synthetic control specification. In this case, we obtain significant effects for the initial 
portion of the sample after the announcement, but the joint p-value is large (0.5), indicating the policy had no permanent effect in inflation ${ }^{1}$.

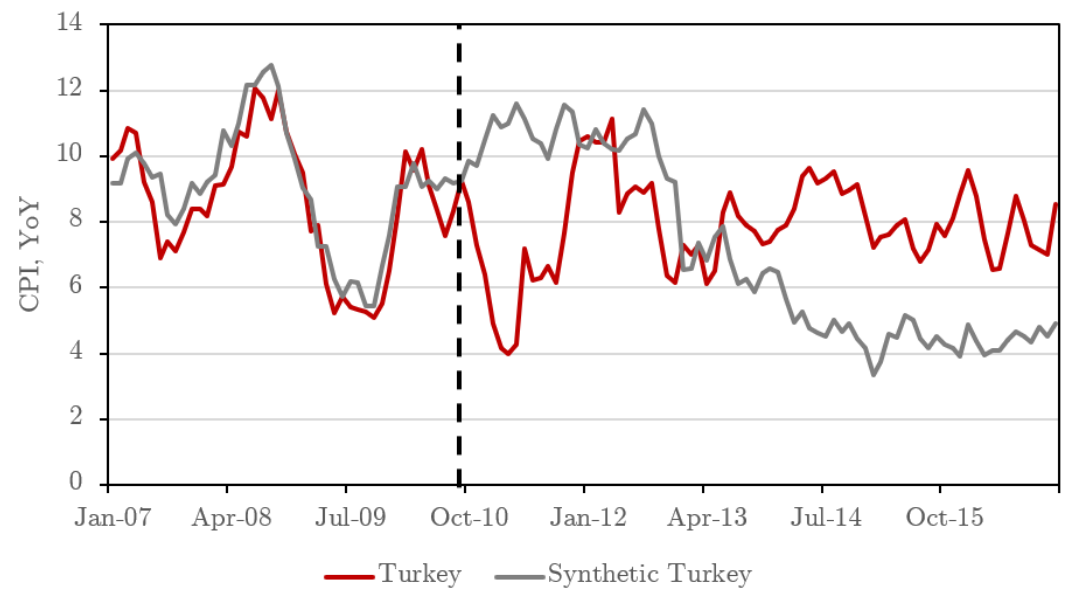

Figure 6.1: Synthetic Control for CPI

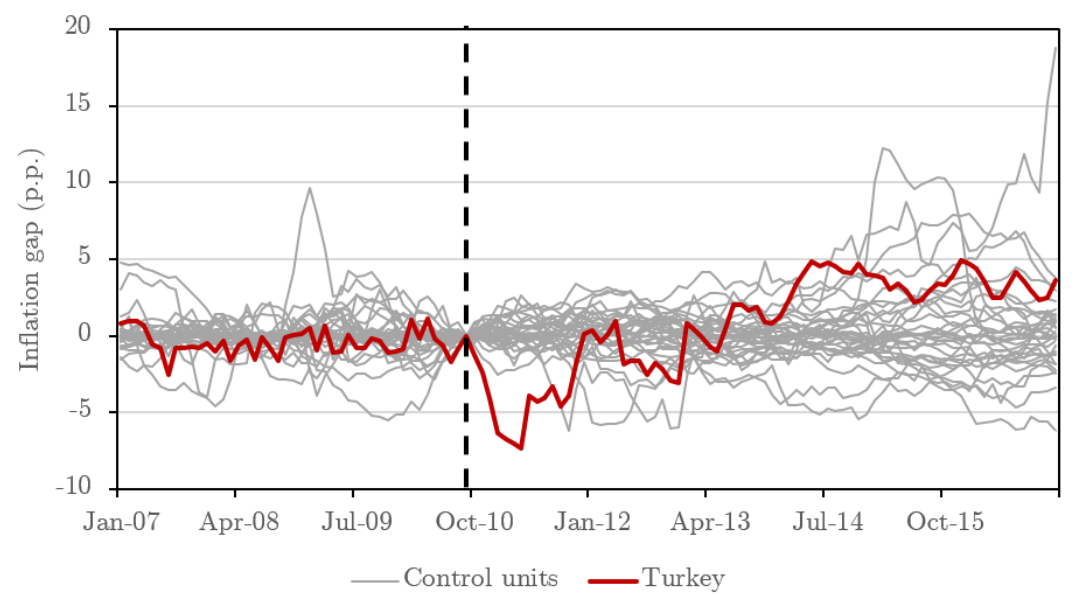

Figure 6.2: CPI Effects

\subsubsection{2}

\section{Exchange Rate}

As mentioned before, the CBRT considered exchange rate an important transmission and communication channel in the new framework. It is also a good measure of international financial stability (Bruno and Shin (2015)). Figure 6.3 presents Turkey's observed exchange rate versus its synthetic counterfactual. Notice that estimates were calculated with the log difference of exchange rate as the outcome variable, but we report the accumulated

${ }^{1}$ It is important to remind that what we call here "p-value" has a different interpretation from the usual statistical inference. It is interpreted as the probability of higher or equivalent effects happen by chance. 
variation, setting the level to 1 on the last observation prior to the intervention. Again, we observe a good fit of the estimated variable before October 2010, although it seems there is a slightly positive bias. The interpretation is more straightforward than in the previous subsection. There is a detachment that persists throughout the whole affected sample, which indicates that the central bank was effective, at least initially, to avoid an overvaluation of the Turkish Lira in a context of current account deterioration. In July 2011, while the Lira had depreciated almost $16 \%$, the potential outcome faced a $7 \%$ appreciation.

Kara (2013) also highlights the action of the CBRT during the euro area debt crisis in 2011. The author argues that it was possible to limit the currency depreciation at the time, relative to other emerging markets. To better assess his claim, we present Figure 6.4, setting the exchange rate in August 2011 to 1 . At the end of that year, synthetic Lira had depreciated more sharply, around $14 \%$ as opposed to an $8 \%$ depreciation in the actual exchange rate. This corroborates the argument of soft-landing in the financial side of the economy: while capital flows were booming, CBRT avoided unsustainable appreciation and, when sovereign debt problems in European Union built up, the new policy fended off a sudden stop and depreciation was more moderate than it would have been without its instruments. In an effort to relate the results of this subsection to the previous one, we can speculate that the first drop in inflation was not associated to exchange rate since the latter went up. Despite it all, the crisis in the euro area pressured both inflation and currency. The estimations suggest the central bank was able to avoid further damage.

Finally, as in the CPI analysis, from 2013 onwards estimated and realized outcomes move apart and. As mentioned before, since we are looking at too many periods ahead the intervention, it is not clear how the new policy might be the direct cause of it. Anyway, to illustrate that gap, at the beginning of 2014, the currency accumulated more than 54\% depreciation albeit it could have been around $22 \%$. 


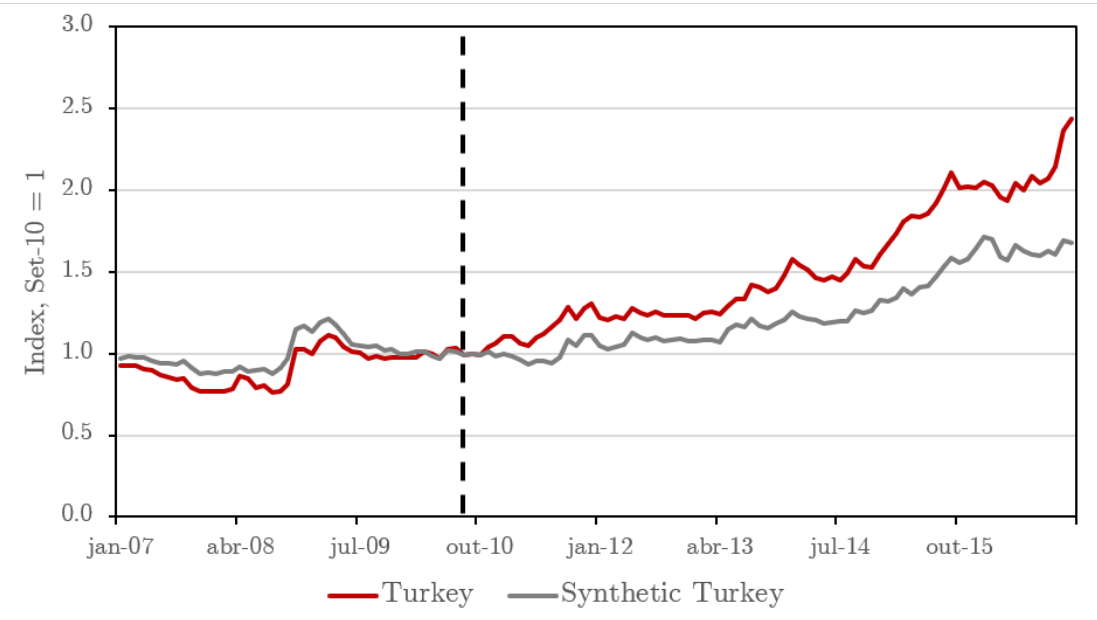

Figure 6.3: Synthetic Control for Exchange Rate

Moving to inference, Figure 6.5 is analogous to Figure 6.2. It displays the gap between observed and estimated outcome for all countries, including Turkey. The fit is a bit loose in the midsection of the pre-intervention data, but the $R^{2}$ of 0.74 is not alarming. After the policy implementation, the effect on Turkey's currency departs from the most of the placebos and remains in that way. Naturally, this becomes more evident at the end of the sample. Checking the graph of period p-values (Figure a), we get significance at the $10 \%$ level for some separate periods, including several leads forward. Nevertheless, the joint p-value of 0.182 indicates no general effect.

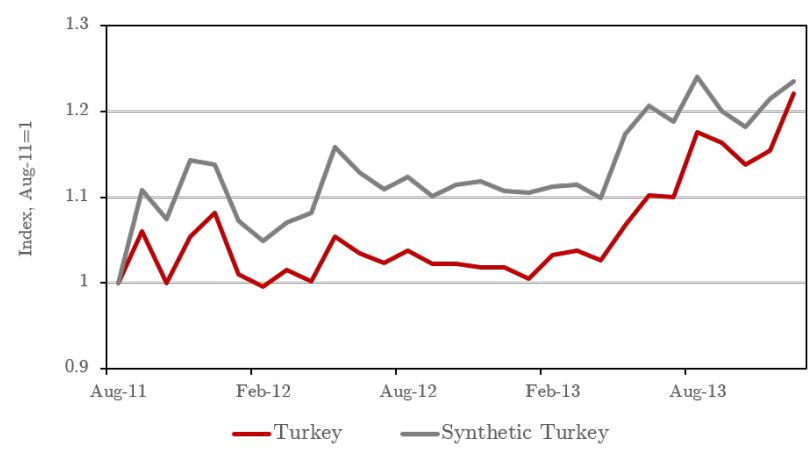

Figure 6.4: Turkish Lira's soft-landing 


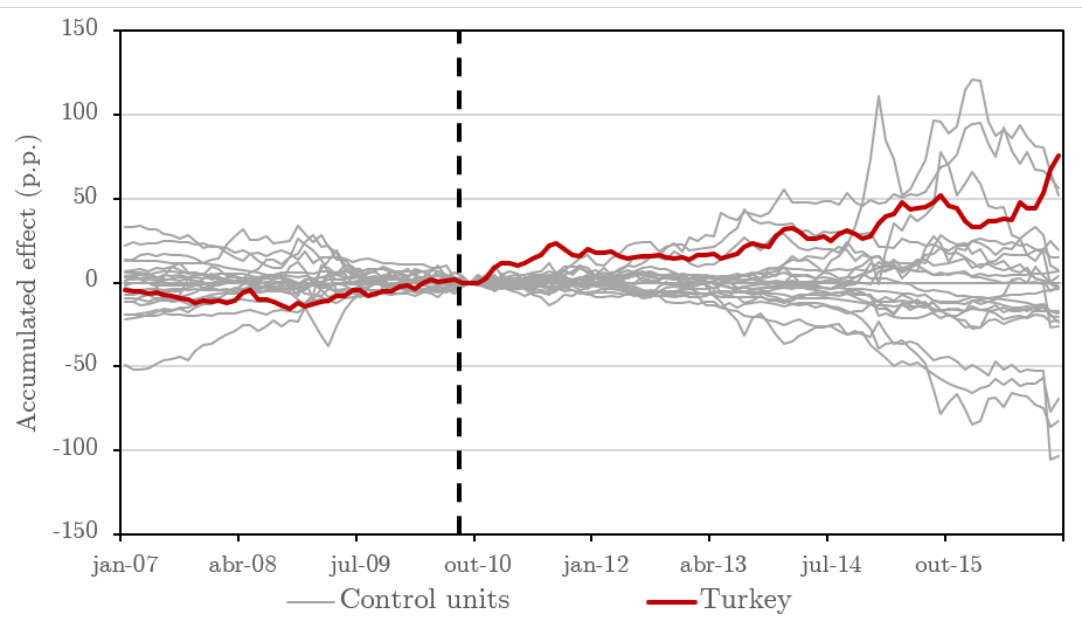

Figure 6.5: Exchange Rate Effects. Note: The values give the percentage point difference between observed and potential accumulated depreciation of the Lira since September 2010

\subsubsection{3 \\ Credit}

Giving sequence to evaluating effects on the intermediate variables of monetary policy, Figure 6.6 exhibits the behavior of domestic credit growth. For better interpretation, we retrieved the original variable the graph represents credit growth. During the months that preceded the new framework, Turkey experienced a rapid growth in credit. Excess of indebtedness was one of the main issues policymakers wanted to tackle with the new tools. As described above, at the end of 2010, the central bank set the interest corridor and required reserves to contain volatile capital and, thus, decrease credit growth. During the next year, debts slowed down, as inflation also reduced. In September 2011, credit decreased around 5\%, while synthetic credit was growing at a $22 \%$ rate. The gap narrowed down in 2012 and then, for the rest of the period, credit growth remained below the potential outcome, but fluctuated similarly. As we have seen previously, in the final portion of the sample, it becomes unclear whether there are still effects originated from the policy. The difference here is that observed and estimated start to move together and keep a small gap between them, especially when both of the variables stabilize at the end of 2013 .

Taking a glance at the graph of placebo effects in Figure 6.7, we can say that this case would benefit from a more stringent exclusion criterion. Since the gaps are very dispersed both before and after the intervention, it is hard to tell if the policy had any effect on credit after all. Nevertheless, it is possible that, in line with the two previous sections, the effects are significant only for 
a brief period of time. However, the p-value graphs in the Appendix (Figure a) does not support this arguement. The joint p-value, once again, suggests no effects of the policy for the period after its implementation.

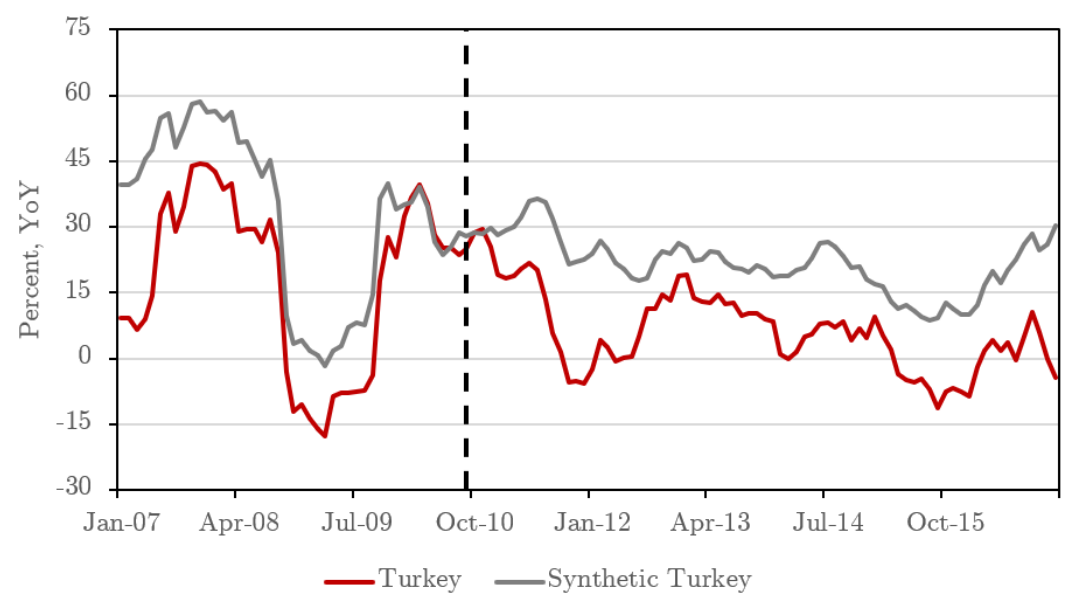

Figure 6.6: Synthetic Control for Domestic Credit Growth

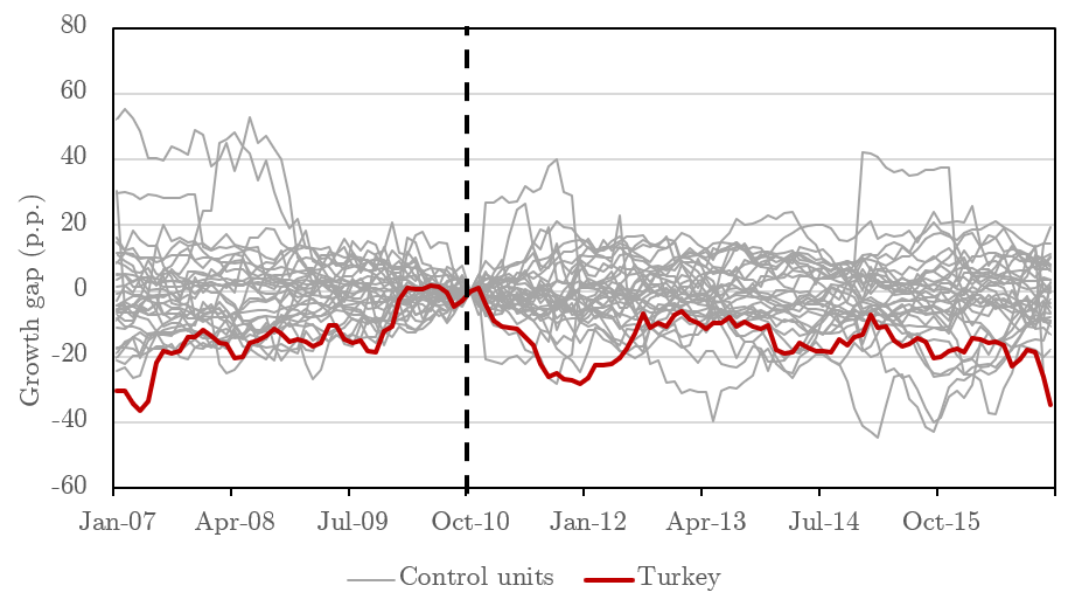

Figure 6.7: Domestic Credit Effects. Notes: The values give the percentage point difference between observed and potential growth of credit since September 2010

\section{0 .2}

\section{Alternative Specifications}

The other two specification were estimated in order to guarantee some robustness in our conclusions and also to evaluate how the SCM is sensitive to model choices. The first alternative we implemented is the use of predictors on their level, without taking differences (Level Specification). The only exception is the exchange rate, since its variation is more informative than its level for this context. In this case we also implement the training-validation procedure, 
following the recommendation by Abadie et al. (2015). The second is using all lags from the outcome variable as predictors, such that the estimator minimizes the quadratic prediction error of the synthetic for every period before the announcement of the policy (Outcome Specification). As mentioned in the review of literature, Kaul et al. (2015) states that the other variables become irrelevant, that is, they are attributed a zero weight in the training period.

We chose the first model because in the literature of application of the SCM, level data are largely used, despite the risks discussed in theoretical papers. Therefore, we wanted to verify if there would be any impact on fitting and results. The second is an interesting case because it is based solely on the outcome variable and ignores economic rationale of determinants of variables. Table A.4 in the Appendix presents the inference statistics.

\subsubsection{1}

\section{CPI}

Figures 6.8, 6.9, 6.10 and 6.11 present the results. None of the alternative specifications yield significant differences from the baseline specification. The fitting of the synthetic during the pre-intervention period seems better than our first estimation. This is confirmed by the $R^{2}$, which gets much bigger with the Outcome Specification, as we expected. Placebo tests and p-values, however, get worse and yet again, there is not statistical significance. What we can infer at least from the graphs is that our story line persists, as there is an intense drop in inflation right after the new policy, but it does not sustain for much longer. According to Figures b and c p-values for unitary periods signal these initial impact is relevant.

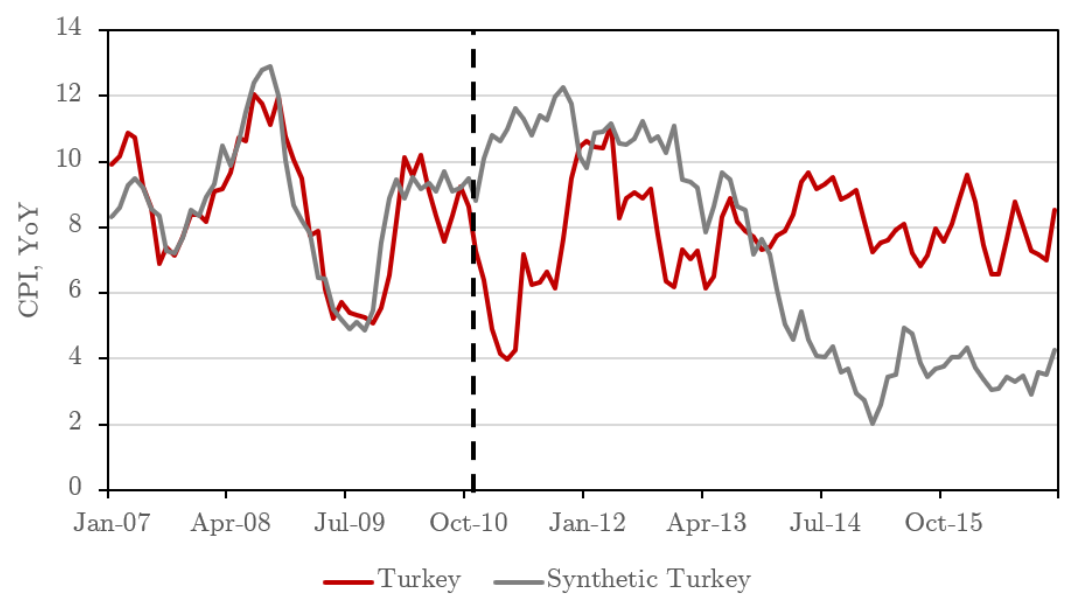

Figure 6.8: Synthetic Control with Level Specification for CPI 


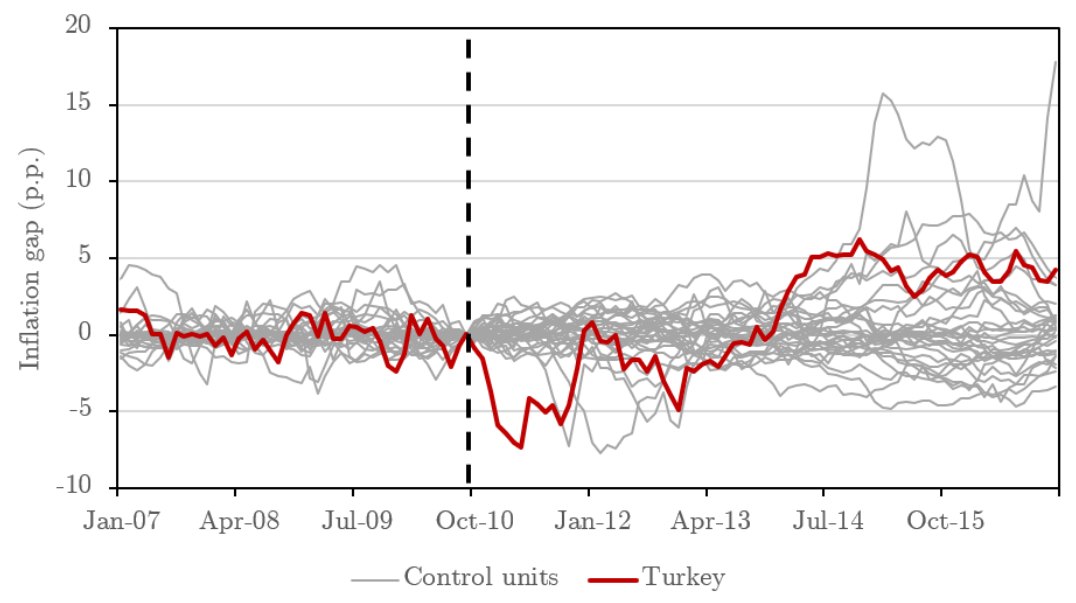

Figure 6.9: CPI Effects with Level Specification

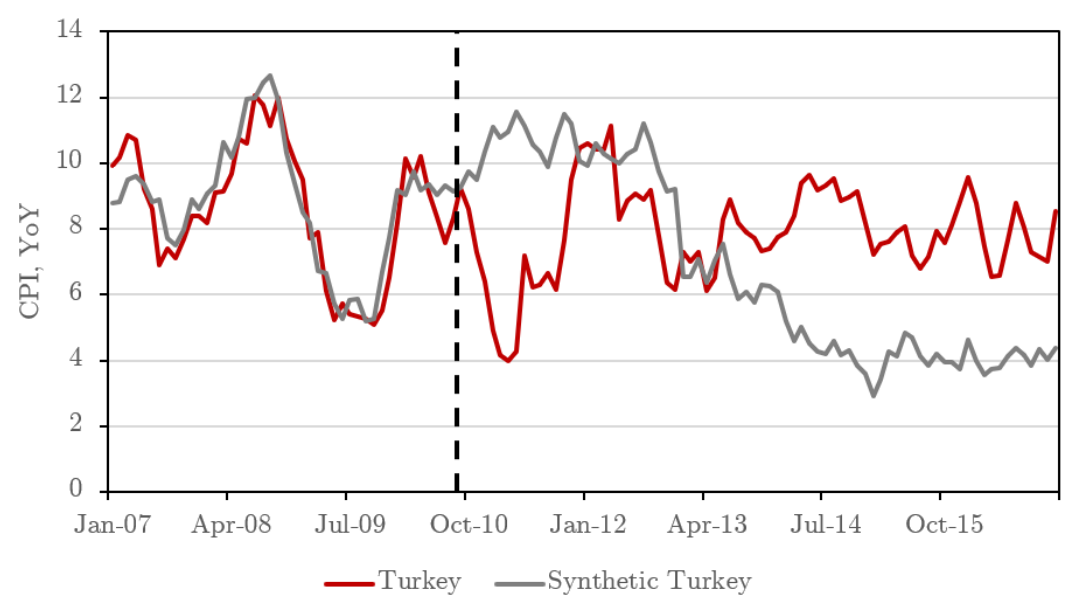

Figure 6.10: Synthetic Control with Outcome Specification for CPI

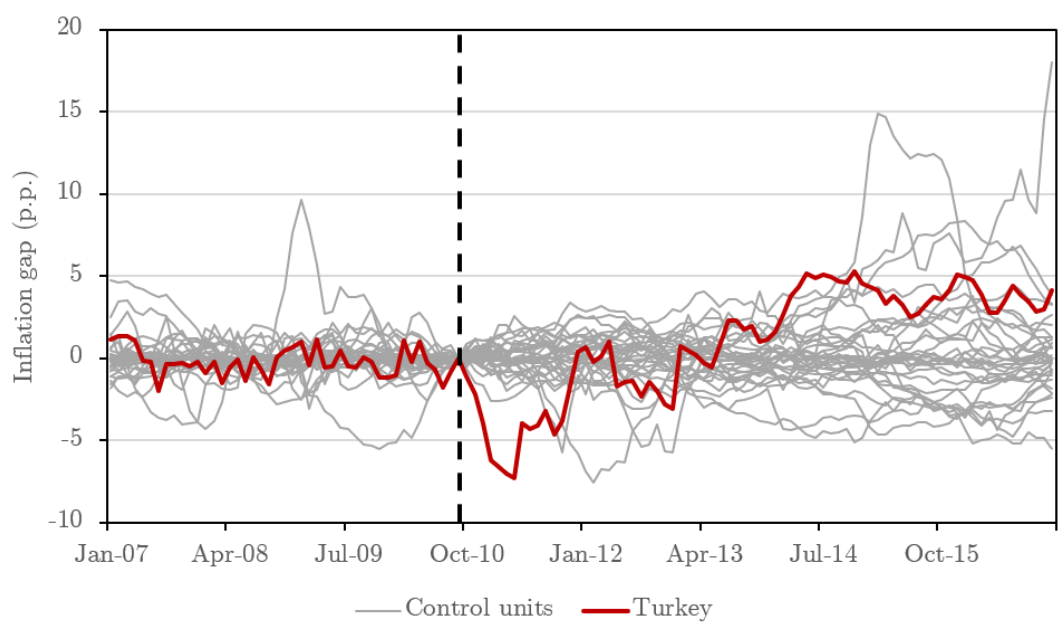

Figure 6.11: CPI Effects with Outcome Specification 


\subsubsection{2}

\section{Exchange Rate}

Figures $6.12,6.13,6.14$ and 6.15 present the results. Both of the specifications are very similar, even when comparing the $R^{2}$. The Level Specification brought synthetic and observed exchange rate really close, but they diverge from 2013 onwards. The joint p-value calculated equals to 0.10 , which makes this model the most significant in our SCM application. The Outcome Specification presents a low p-value as well, but it stands out for its placebo tests. Accumulated effects are considerably higher than in other countries throughout the post-intervention period. This reiterates the argument that, during the first year of the new policy stance, the CBRT achieved its goal to avoid over valuation of the Turkish Lira. However, at some point in time, the depreciation of domestic currency started to accelerate more than intended.

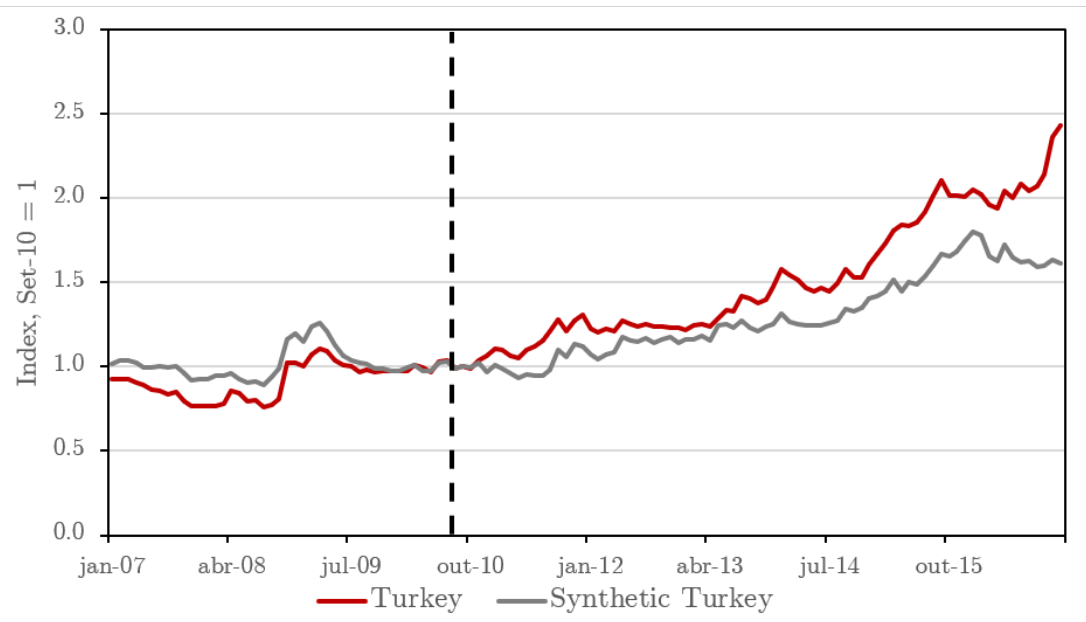

Figure 6.12: Synthetic Control with Level Specification for Exchange Rate

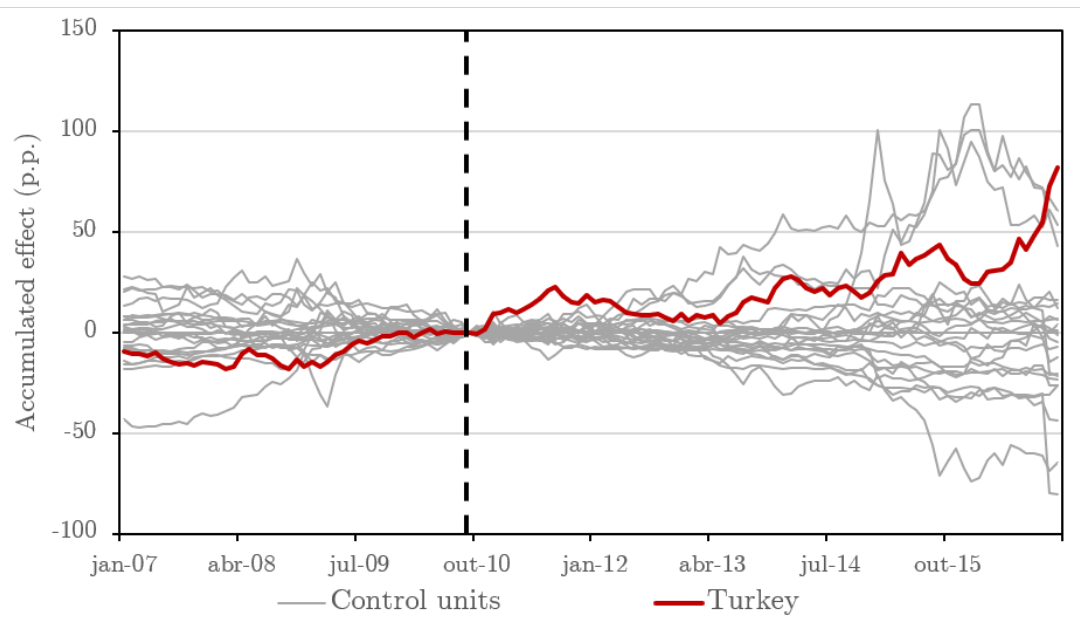

Figure 6.13: Exchange Rate Effects with Level Specification 


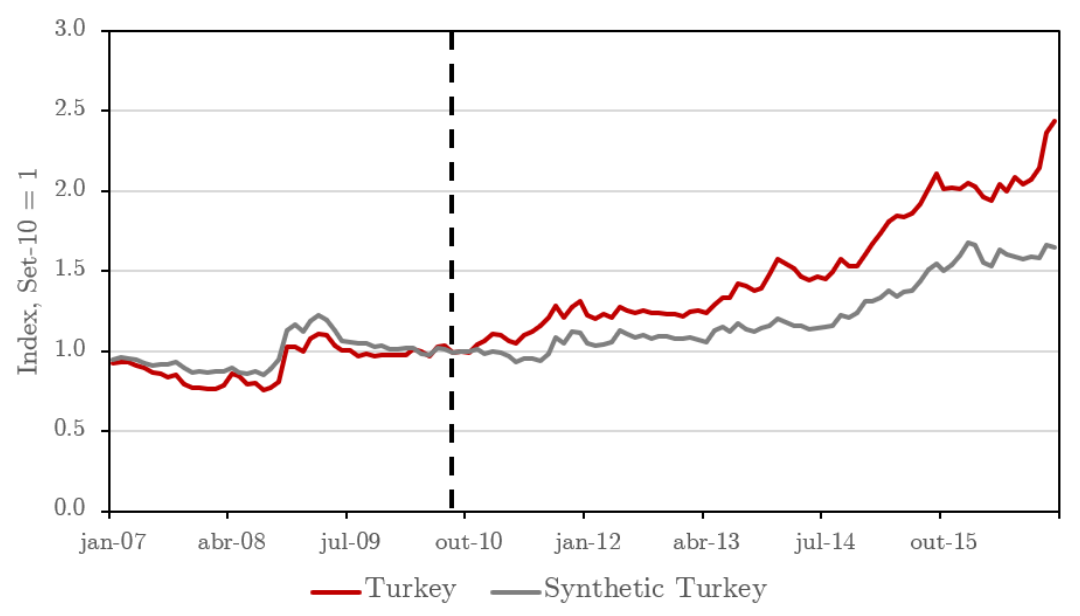

Figure 6.14: Synthetic Control with Outcome Specification for Exchange Rate

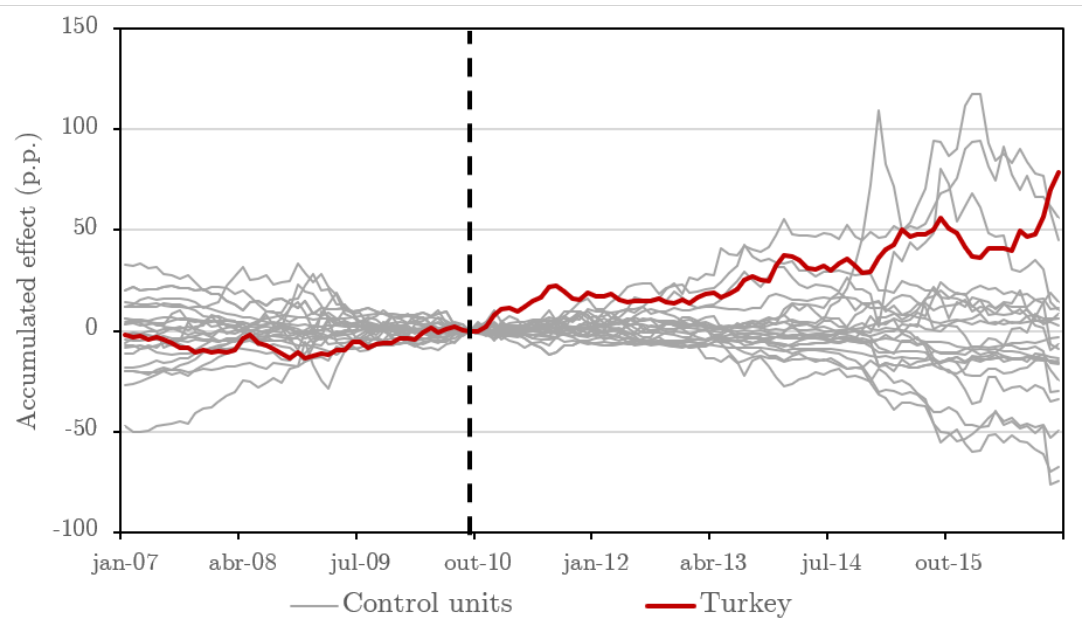

Figure 6.15: Exchange Rate Effects with Outcome Specification

\subsubsection{3}

\section{Credit}

Figures 6.16, 6.17, 6.18 and 6.19 present the results. Despite demonstrating the best fitting in terms of $R^{2}$ during the pre-intervention period, credit analysis in the SCM remains inconclusive. In the same way we checked that the Level Specification brought synthetic and observed exchange rate closer, the estimated and the actual level of credit are not so distant. Hence, it is more difficult to draw a conclusion. Interpretation of the placebo effects graphs lead to possibly no effect at all. They are not informative, especially because the pre-treatment fit is poor for a considerable number of countries. This suggests some issue with the data or with the control and variable choices. 


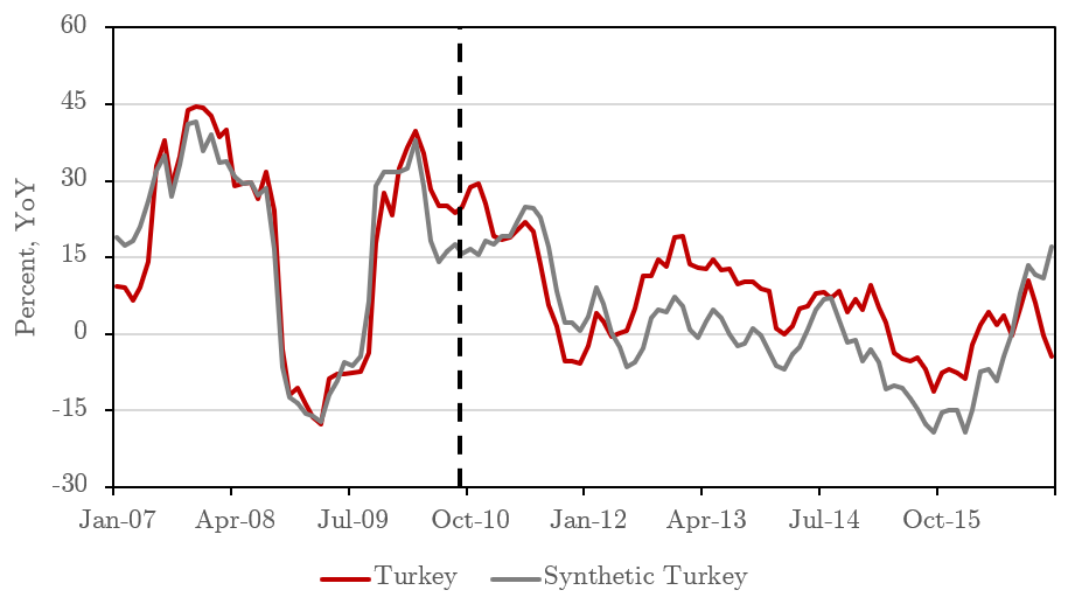

Figure 6.16: Synthetic Control with Level Specification for Credit

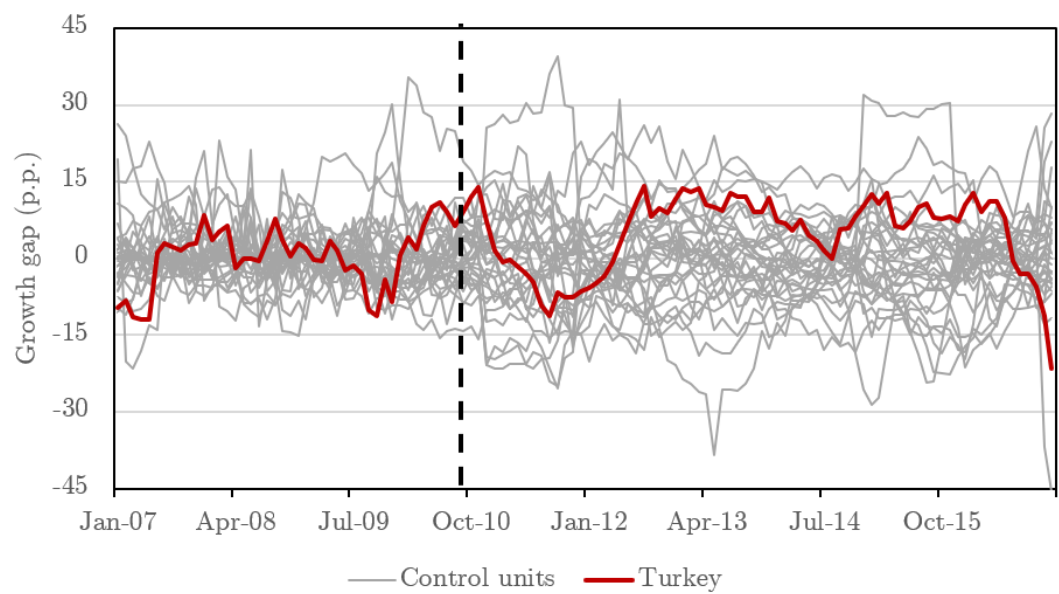

Figure 6.17: Credit Effects with Level Specification

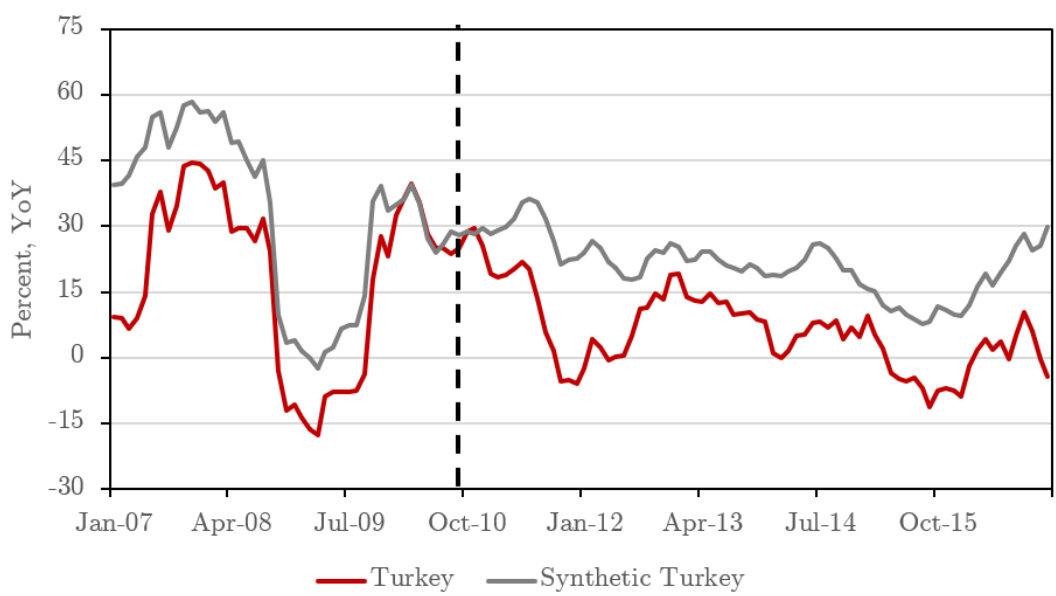

Figure 6.18: Synthetic Control with Outcome Specification for Credit 


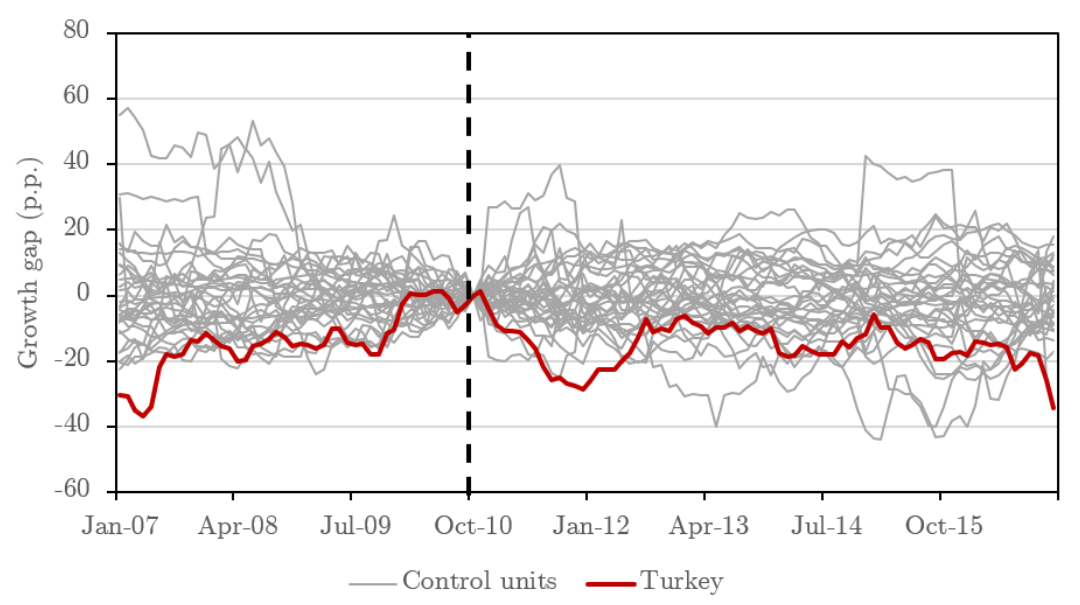

Figure 6.19: Credit Effects with Outcome Specification

\subsection{3}

\section{Artificial Counterfactual}

The Artificial Counterfactual estimator proposed by Carvalho et al. (2016) presents a series of advantages in comparison to the synthetic control that will be very useful for our analysis. First of all, we are able to estimate effects for all outcome variables at the same time. Furthermore, we have access to a direct inference procedure and hypothesis testing, even for the multivariate case. We cannot forget although, that assumptions in the SCM are different from the ArCo. Figures 6.20, 6.21 and 6.23 show our three outcome variables versus their estimates. The model we chose to get the parameters is the LASSO estimator, as described in Section 4.

Inflation results are very similar to what we presented with the SCM. There is a fast drop in CPI right after the announcement of the intervention while the counterfactual remained at high levels. A few months later, the variables met and took a similar path. The visible difference here is that, at the end of the sample, they do not diverge, reinforcing the idea that the policy offered only short-term effects and did not change its potential trajectory. However, as in the SCM, we should look at long term predictions with parsimony. ArCo outputs generate a vector of individual p-values for each variable and a joint one. The hypothesis tested in this method is regarding the average effect of the treatment, rather than significant effects for all periods. Table A.7 contains the outputs. The average effect on inflation is not significant. 


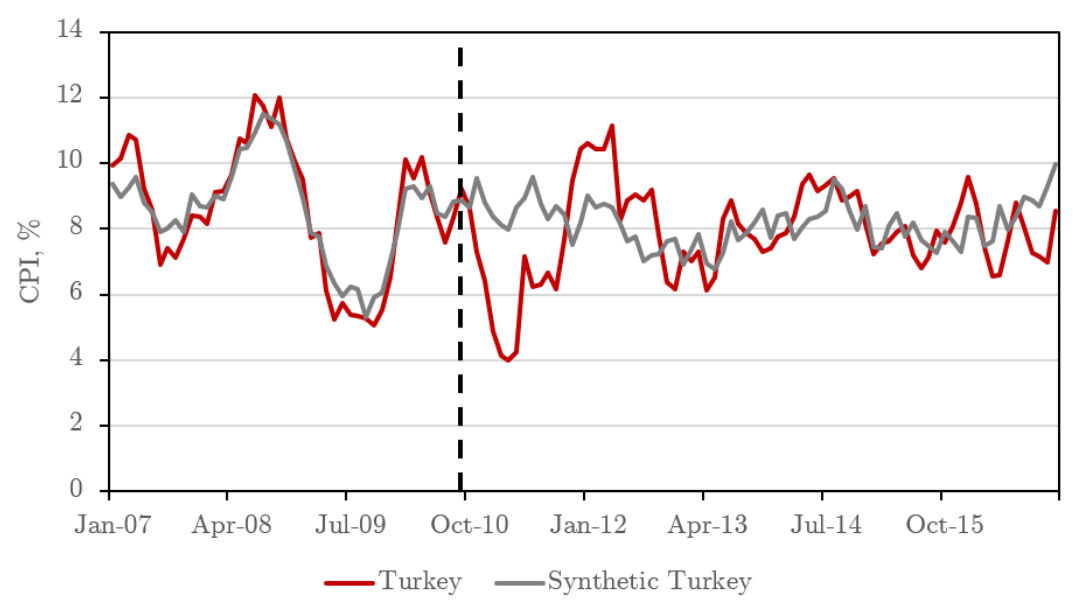

Figure 6.20: ArCo for CPI

Next, we have the accumulated variation of exchange rates in Figure 6.21. The estimated counterfactual is very similar to the one produced by the synthetic control, despite an apparently better fit before the shift in monetary policy. For example, in July 2011, the Turkish Lira could have appreciated 5\%, close to the $7 \%$ estimation in the SCM. The detachment here is very clear, as well as the smoother depreciation during the euro crisis. Again, they do not signal the will meet and present a fast broadening. It might be interesting to notice that the gap between them in the ArCo gets larger than in the $\mathrm{SCM}$, as the potential value of dollar never surpasses the 1.5 mark (50\% depreciation). Nevertheless, the p-value provided by the model indicates no significance. It is important to remind that these graphs come from transformed and accumulated data. For "raw" estimations, as provide by the ArCo method, please check Appendix D, where it is possible to check the fit and deviation between observed and estimated.

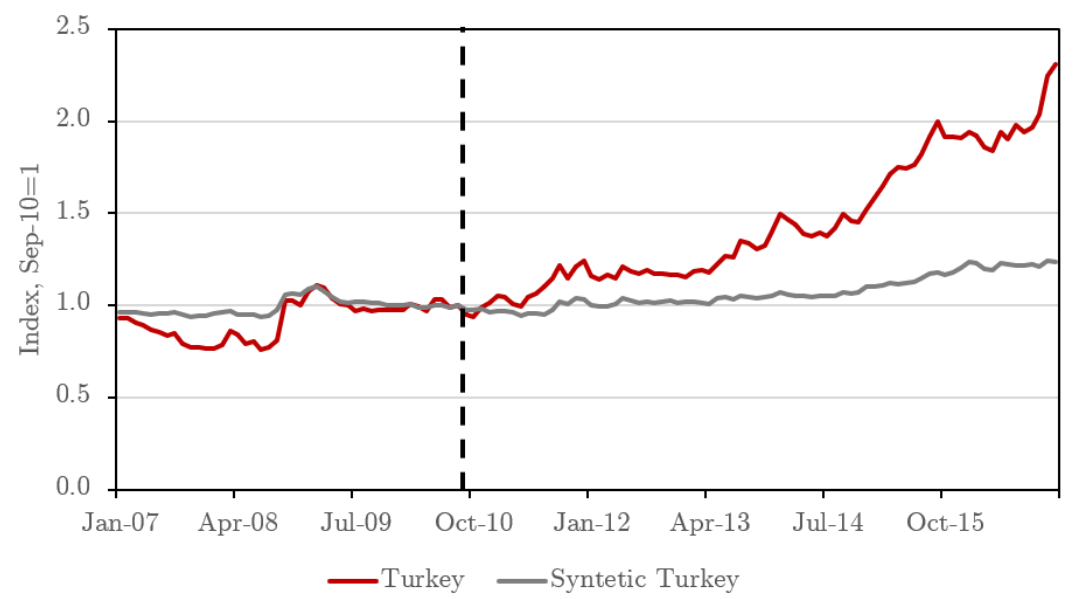

Figure 6.21: ArCo for Exchange Rate 
Lastly, Figure 6.23 presents an interesting result from the ArCo estimation. It depicts a strong indebtedness trajectory for Turkey, had it not adopted the new policy stance. Domestic credit growth would have accelerated for the next years, while we observed a relative stabilization. Thus, while we were not getting substantial and persistent reaction from other economic variables, credit seems to have shifted from a very dangerous path. It is possible that the central bank was able to slow down incoming capitals, by promoting interest rate daily volatility and respond quickly to markets' inconsistency. Indeed, in its 2012 annual report, the CBRT claims it actively acted against credit growth, which, in turn, is highly correlated to current account deficits. Through required reserve ratios, liquidity policy, capital adequacy risk weights, general provisions and loan-to-value ratio, the central bank set a target for net credit utilization ratio. Believing balanced growth of credit was essential for financial stability, policymakers affirm they managed to elevate credit costs.

However, looking at Table A.7, effects on credit are not significant. It is hard to say that the decrease in credit growth was not also related to capital flights after the debt crisis in the euro area. Still, the new framework may have paved the way for stability and sovereignty in the Turkish financial system. An interesting result that stemmed from the ArCo estimation is the joint p-value, which suggests significance of the general model. Table A.6 depicts the average estimated effect and the interval confidence and it shows that only the effect on credit stays entirely in the negative range.

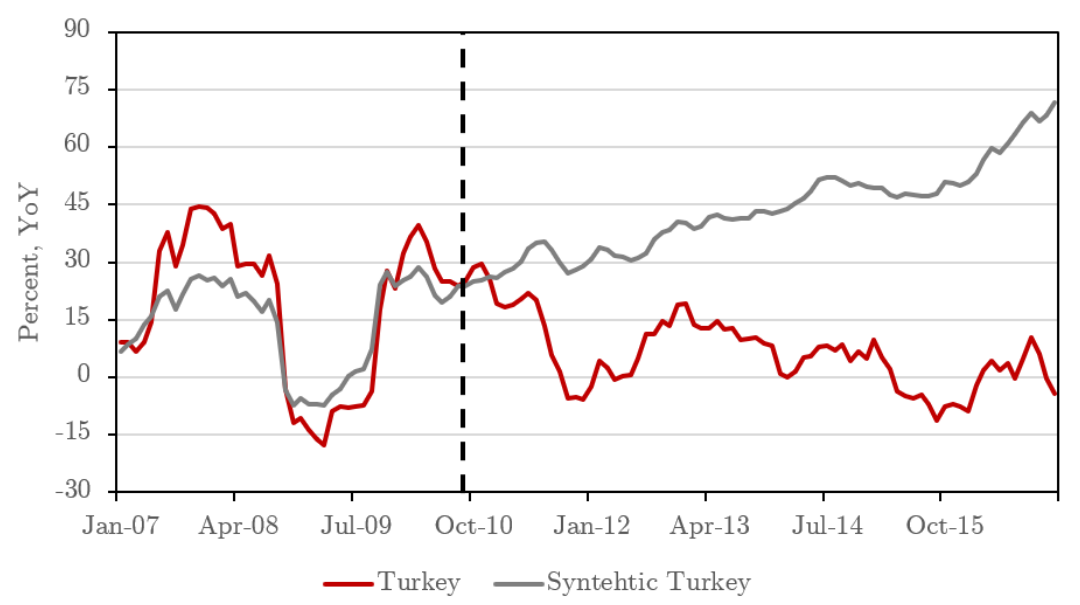

Figure 6.22: ArCo for Domestic Credit

Another issue we have discussed previously is the choice of a representative credit variable that would capture the decisions from the Central Bank. Our original variable is a general measure of domestic credit that would include different sectors of society. In order to obtain more robust results, we 
have estimated the artificial counterfactual with an alternative variable, from the IMF, described as domestic claims in the financial system. First of all, regarding inflation and exchange rate effects, there were no additional insights from what we have already argued ${ }^{2}$. Nevertheless, credit estimations were once again noteworthy. This time, the individual average effect of the new policy stance is significant, but looking at the graphic, we derive the impact on credit only started by mid-2011, leading to the highest gap between observed and synthetic by September 2012.

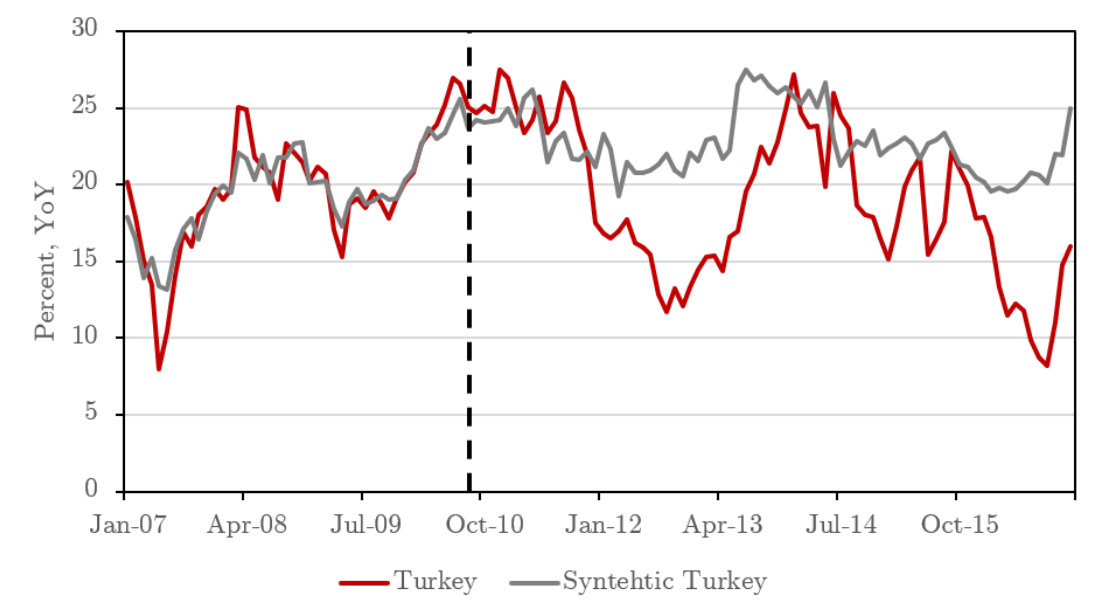

Figure 6.23: ArCo for Domestic Credit with alternative data

The results gathered in this section provided some insights. After applying the SCM and ArCo, we argue that one of the main issues, as pointed out discussed in the literature, is the inference procedure of the SCM, which is still under development. Studies like Firpo and Possebom (2017) and Klößner and Pfeifer (2015) might help validation and comparison with other methods, specially when dealing with multiple variables that can explain each other, as well as time series. Then we encourage the use of SCM for macroeconomic policies but also draw attention to its limitations as an estimator. On the counterpart, the ArCo proved to be very useful, not only by the straightforward inference, but by its flexibility when choosing the model function. In our case, the choice of LASSO alleviated the burden of specification choice, which is recurrent in the SCM. 


\section{Conclusions}

In this paper we evaluated the effects of a shift in the monetary policy stance in Turkey. The country, as many other emerging markets, was experiencing intense capital flows after the financial crisis. Excess of liquidity became a potential problem, as exposure to global risk appetite could determine domestic fluctuations. So the Central Bank of the Republic of Turkey decided to implement a non-conventional monetary policy framework with multiple interest rates and liquidity management. The monetary authority aimed at both price and financial stability.

Thus, our purpose was to use modern data-driven comparative case methods, in order to measure the possible impacts of such change on crucial financial variables: inflation, exchange rate and domestic credit. We relied on Abadie et al. (2015) and Carvalho et al. (2016) to achieve our goal. Our estimations for both methods points to little or no effect on the variables of interest, despite some temporary efficiency of the new policy during the first year of it. Inflation presented a considerable drop in 2011 when compared to the potential outcome. Exchange rate did not over-appreciate during capital inflows and did not crumble during capital flights. Meanwhile, according to ArCo estimator, the new policy might have prevented credit from following an explosive path.

We hope this paper contributes to two different areas of interest. Firstly, the analysis of alternative tools for executing monetary and macro-prudential policies. Secondly, the use and comparison of counterfactual construction methods, especially in macroeconomics. We also encourage further study on the case of Turkey due to its great potential to find proper synthetic controls. Data that comprehends flows of capitals, maturity composition, current account deficits, volatility, and so on should also be considered. Our results points to no great impact on basic monetary variables, but given that credit possibly underwent a significant shift in trend, it is valuable to investigate this transmission channel as well. 


\section{8 \\ Bibliography}

Abadie, A., Diamond, A., and Hainmueller, J. (2010). Synthetic control methods for comparative case studies: Estimating the effect of california's tobacco control program. Journal of the American statistical Association, 105(490):493-505.

Abadie, A., Diamond, A., and Hainmueller, J. (2015). Comparative politics and the synthetic control method. American Journal of Political Science, 59(2):495-510.

Abadie, A. and Gardeazabal, J. (2003). The economic costs of conflict: A case study of the basque country. American economic review, 93(1):113-132.

Athey, S. and Imbens, G. W. (2017). The state of applied econometrics: Causality and policy evaluation. Journal of Economic Perspectives, 31(2):3-32.

Beau, D., Clerc, L., and Mojon, B. (2012). Macro-prudential policy and the conduct of monetary policy.

Benigno, G., Chen, H., Otrok, C., Rebucci, A., and Young, E. R. (2013). Financial crises and macro-prudential policies. Journal of International Economics, 89(2):453-470.

Billmeier, A. and Nannicini, T. (2013). Assessing economic liberalization episodes: A synthetic control approach. Review of Economics and Statistics, 95(3):9831001.

Binici, M., Kara, H., and Özlü, P. (2016). Unconventional interest rate corridor and the monetary transmission: evidence from turkey. Technical report.

Bruno, V. and Shin, H. S. (2015). Capital flows and the risk-taking channel of monetary policy. Journal of Monetary Economics, 71:119-132.

Carvalho, C., Masini, R., and Medeiros, M. C. (2016). Arco: An artificial counterfactual approach for high-dimensional panel time-series data. Available at SSRN: https://ssrn.com/abstract $=2823687$.

Chamon, M., Garcia, M., and Souza, L. (2017). Fx interventions in brazil: a synthetic control approach. Journal of International Economics, 108:157-168. 
Claessens, S., Ghosh, S. R., and Mihet, R. (2013). Macro-prudential policies to mitigate financial system vulnerabilities. Journal of International Money and Finance, 39:153-185.

Ferman, B. and Pinto, C. (2017). Placebo tests for synthetic controls.

Ferman, B. and Pinto, C. (2018). Revisiting the synthetic control estimator.

Ferman, B., Pinto, C., and Possebom, V. (2018). Cherry picking with synthetic controls.

Firpo, S. and Possebom, V. (2017). Synthetic control method: Inference, sensitivity analysis and confidence sets. Journal of Causal Inference, (20160026). Available at https://www.degruyter.com/view/j/jci.aheadof-print/jci-2016-0026/jci-2016-0026.xml.

Fratzscher, M., Lo Duca, M., and Straub, R. (2018). On the international spillovers of us quantitative easing. The Economic Journal, 128(608):330-377.

Jiménez, G., Ongena, S., Peydró, J.-L., and Saurina, J. (2012). Credit supply and monetary policy: Identifying the bank balance-sheet channel with loan applications. American Economic Review, 102(5):2301-26.

Jinjarak, Y., Noy, I., and Zheng, H. (2013). Capital controls in brazil-stemming a tide with a signal? Journal of Banking \& Finance, 37(8):2938-2952.

Kara, A. H. (2013). Monetary policy after the global crisis. Atlantic Economic Journal, 41(1):51-74.

Kaul, A., Klößner, S., Pfeifer, G., and Schieler, M. (2015). Synthetic control methods: Never use all pre-intervention outcomes as economic predictors.

Klößner, S. and Pfeifer, G. (2015). Synthesizing cash for clunkers: Stabilizing the car market, hurting the environment.

Lavigne, R., Sarker, S., Vasishtha, G., et al. (2014). Spillover effects of quantitative easing on emerging-market economies. Bank of Canada Review, 2014(Autumn):23-33.

Pinotti, P. (2015). The economic costs of organised crime: Evidence from southern italy. The Economic Journal, 125(586):F203-F232.

Sanso-Navarro, M. (2011). The effects on american foreign direct investment in the united kingdom from not adopting the euro. JCMS: Journal of Common Market Studies, 49(2):463-483. 


\section{Appendix}

\section{A.1}

\section{The CBRT Policy}

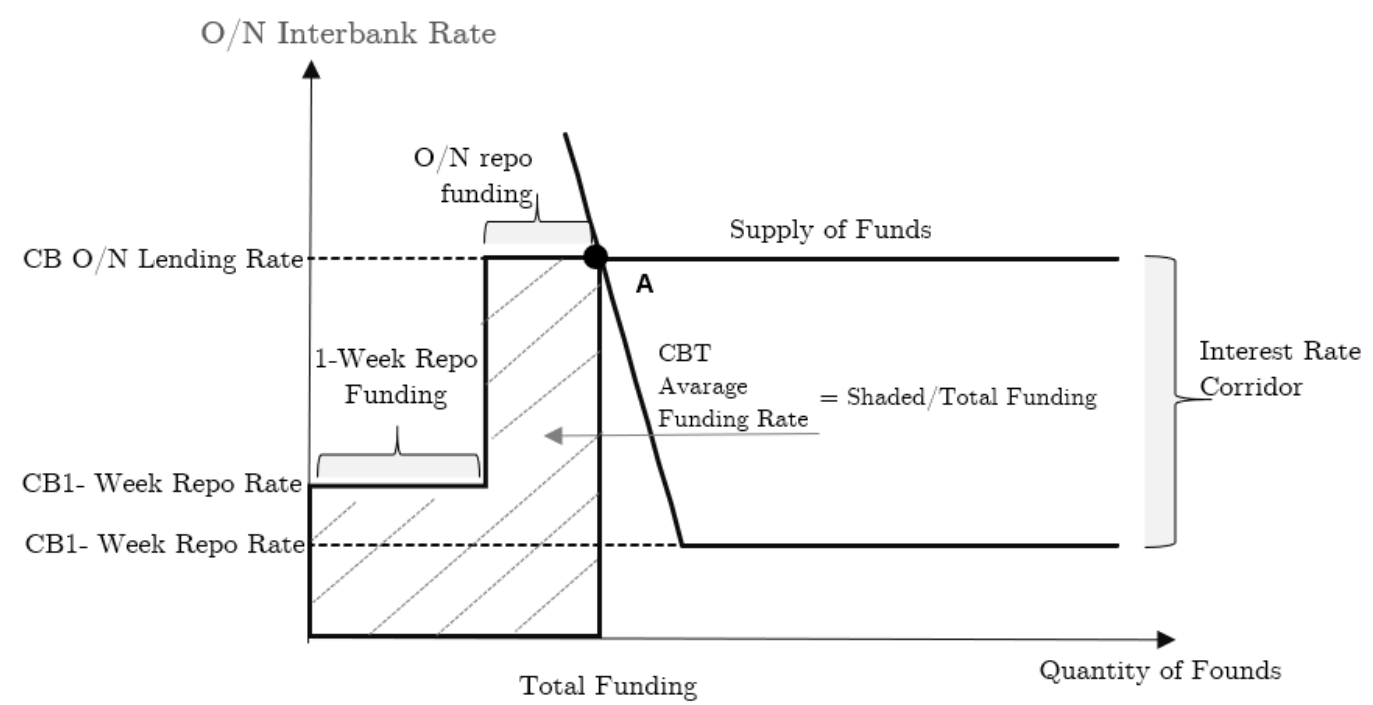

Figure A.1: Supply and Demand for Funding in the CBRT New Policy Mix. Notes: The central bank chooses the amount of funding to supply in one-week repo auctions. If it is less than the liquidity necessity from banks, then the funding rate becomes the $\mathrm{O} / \mathrm{N}$ lending rate. The average funding rate of the central bank is the weighted average of both operations (shaded area in the graphic). 
A. 2

Data

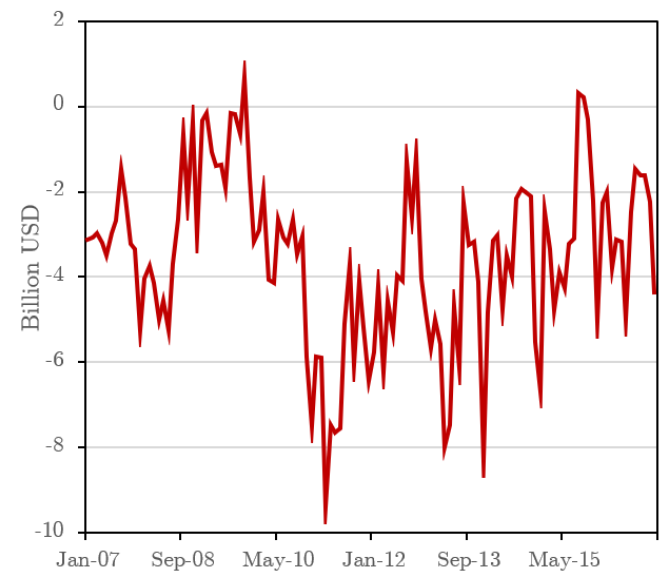

Figure A.2: Trade Balance in Turkey
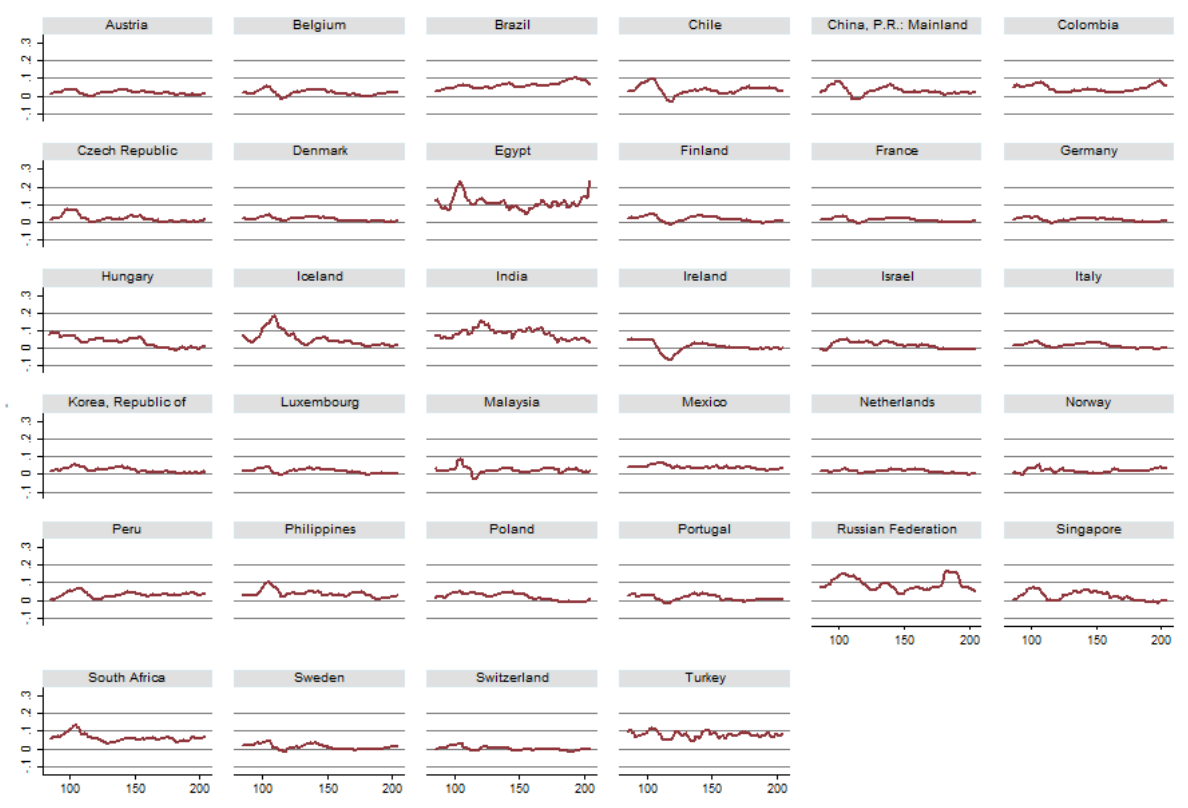

Figure A.3: CPI for all controls (\%) 


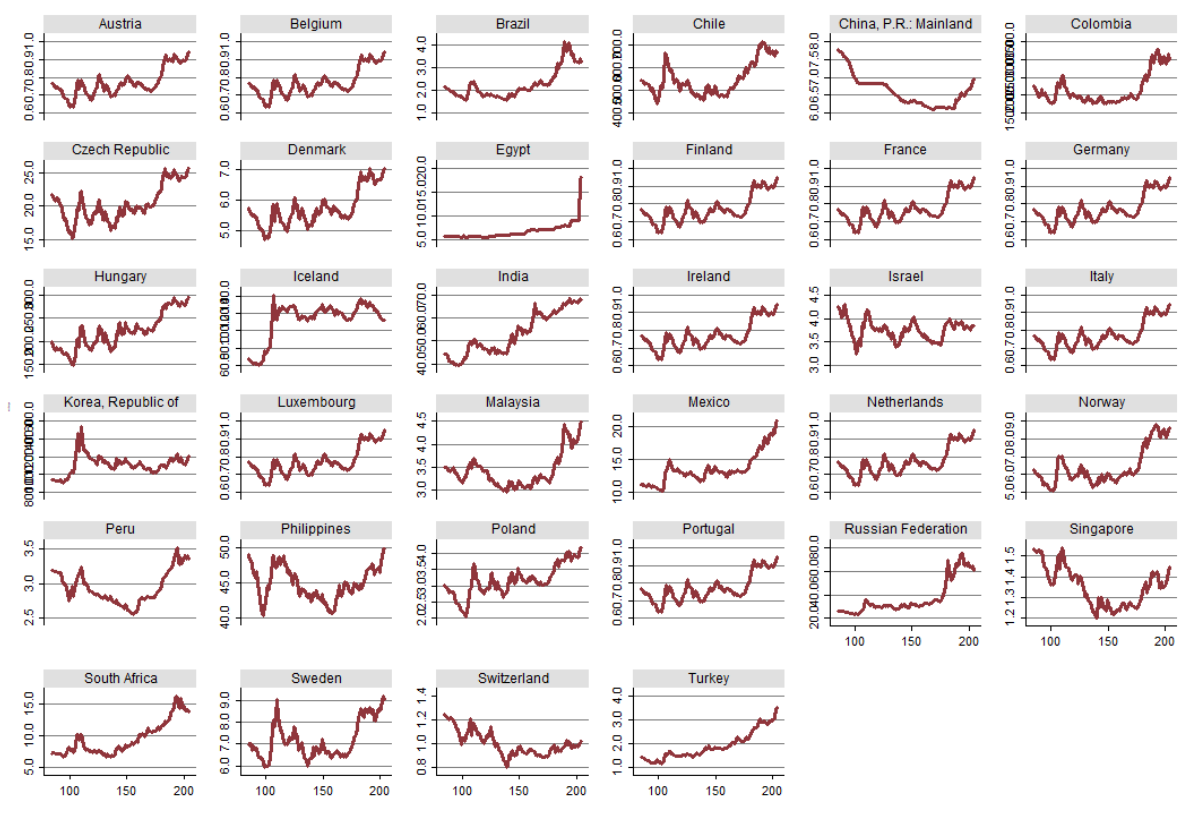

Figure A.4: Exchange Rate in all controls (level)

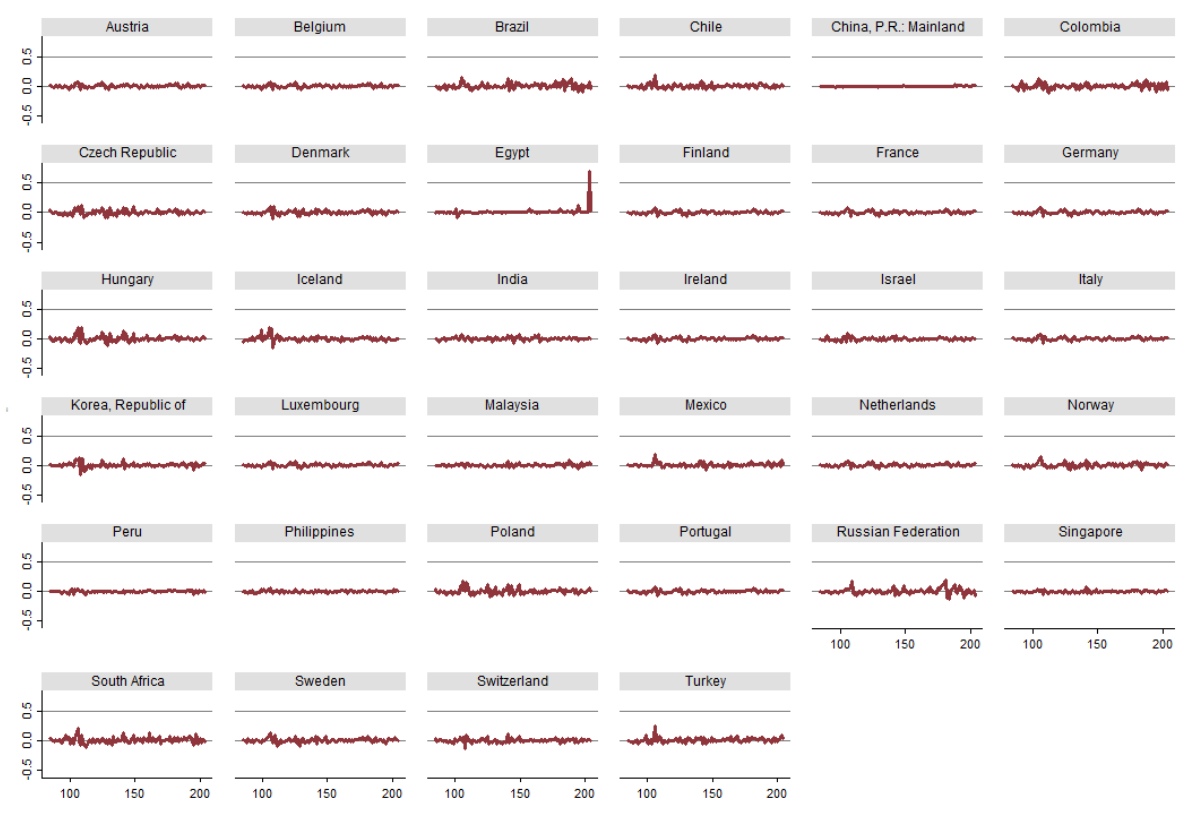

Figure A.5: Exchange Rate in all controls (variation) 


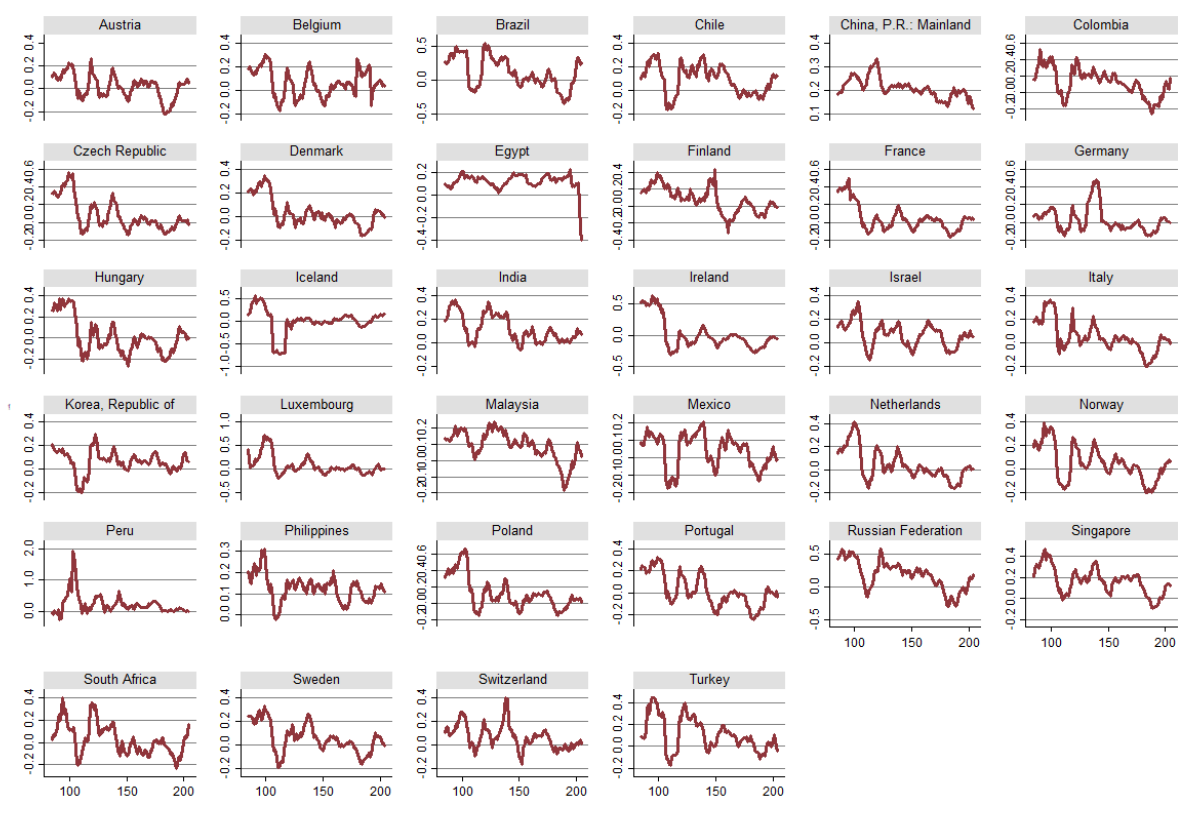

Figure A.6: Credit growth in all controls (\%)
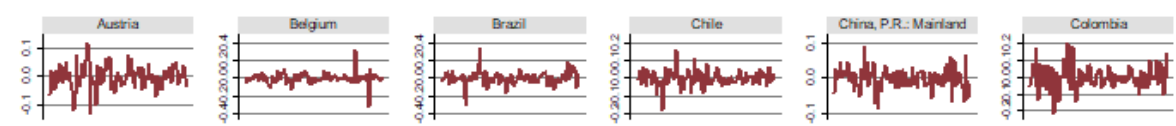

Crectinembic
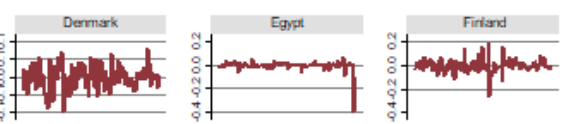

Prance

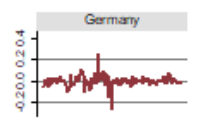

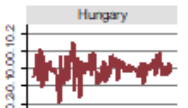
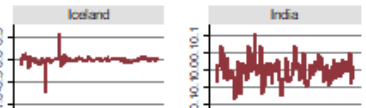

todind

lesad

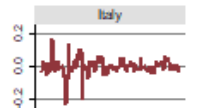

Kres, Reopitic or
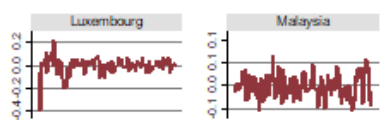

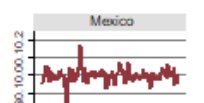

Nothelands

\begin{tabular}{l|l} 
Naway \\
\hline
\end{tabular}
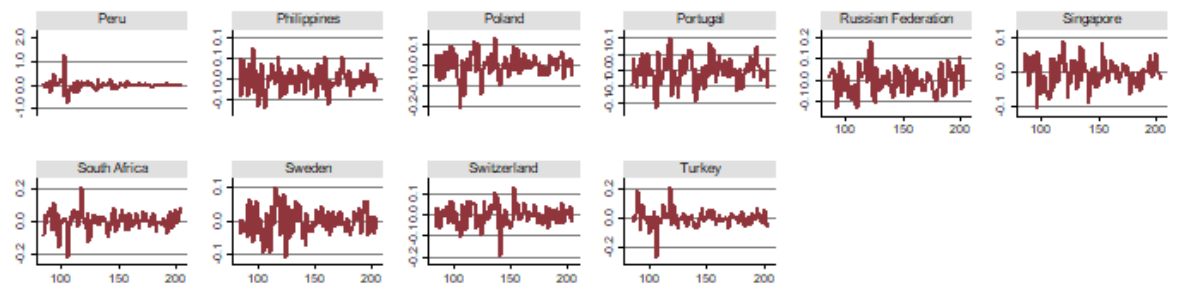

Figure A.7: First difference of credit growth in all controls (p.p.) 


\section{A.3}

Synthetic Control Estimates

\begin{tabular}{|c|c|c|c|c|}
\hline & Country & Baseline & Level & Outcome \\
\hline & Austria & 0 & 0 & 0 \\
\hline & Belgium & 0 & 0 & 0 \\
\hline & Brazil & 0 & 0 & 0 \\
\hline & Chile & 0 & 0 & 0 \\
\hline & China, P.R.: Mainland & 0 & 0.021 & 0 \\
\hline & Colombia & 0.058 & 0 & 0 \\
\hline & Czech Republic & 0 & 0 & 0 \\
\hline & Denmark & 0 & 0 & 0 \\
\hline & Egypt & 0.352 & 0.361 & 0.370 \\
\hline & Finland & 0 & 0 & 0 \\
\hline & France & 0 & 0 & 0 \\
\hline & Germany & 0 & 0 & 0 \\
\hline & Hungary & 0.537 & 0.558 & 0.318 \\
\hline & Iceland & 0 & 0 & 0 \\
\hline & India & 0.053 & 0.061 & 0.163 \\
\hline & Ireland & 0 & 0 & 0.150 \\
\hline & Israel & 0 & 0 & 0 \\
\hline & Italy & 0 & 0 & 0 \\
\hline & Korea, Republic of & 0 & 0 & 0 \\
\hline & Luxembourg & 0 & 0 & 0 \\
\hline & Malaysia & 0 & 0 & 0 \\
\hline & Mexico & 0 & 0 & 0 \\
\hline & Netherlands & 0 & 0 & 0 \\
\hline & Norway & 0 & 0 & 0 \\
\hline & Peru & 0 & 0 & 0 \\
\hline & Philippines & 0 & 0 & 0 \\
\hline & Poland & 0 & 0 & 0 \\
\hline & Portugal & 0 & 0 & 0 \\
\hline & Russian Federation & 0 & 0 & 0 \\
\hline & Singapore & 0 & 0 & 0 \\
\hline & South Africa & 0 & 0 & 0 \\
\hline & Sweden & 0 & 0 & 0 \\
\hline & Switzerland & 0 & 0 & 0 \\
\hline
\end{tabular}

Table A.1: Estimated weights for CPI with the SCM 


\begin{tabular}{|c|c|c|c|}
\hline Country & Baseline & Level & Outcome \\
\hline Austria & 0 & 0 & 0 \\
\hline Belgium & 0 & 0 & 0 \\
\hline Brazil & 0.047 & 0.069 & 0.039 \\
\hline Chile & 0 & 0 & 0 \\
\hline $\begin{array}{l}\text { China, P.R.: } \\
\text { Mainland }\end{array}$ & 0 & 0 & 0 \\
\hline Colombia & 0 & 0 & 0.005 \\
\hline Czech Republic & 0 & 0 & 0 \\
\hline Denmark & 0 & 0 & 0 \\
\hline Egypt & 0 & 0 & 0 \\
\hline Finland & 0 & 0 & 0 \\
\hline France & 0 & 0 & 0 \\
\hline Germany & 0 & 0 & 0 \\
\hline Hungary & 0.049 & 0.132 & 0.128 \\
\hline Iceland & 0.101 & 0.122 & 0.116 \\
\hline India & 0 & 0 & 0 \\
\hline Ireland & 0 & 0 & 0 \\
\hline Israel & 0 & 0 & 0.11 \\
\hline Italy & 0 & 0 & 0 \\
\hline $\begin{array}{l}\text { Korea, } \\
\text { Republic of }\end{array}$ & 0 & 0 & 0 \\
\hline Luxembourg & 0 & 0 & 0 \\
\hline Malaysia & 0 & 0 & 0 \\
\hline Mexico & 0 & 0 & 0.302 \\
\hline Netherlands & 0 & 0 & 0 \\
\hline Norway & 0 & 0 & 0 \\
\hline Peru & 0 & 0 & 0 \\
\hline Philippines & 0.197 & 0.19 & 0 \\
\hline Poland & 0.242 & 0.17 & 0.048 \\
\hline Portugal & 0 & 0 & 0 \\
\hline $\begin{array}{l}\text { Russian } \\
\text { Federation }\end{array}$ & 0 & 0 & 0 \\
\hline Singapore & 0 & 0 & 0 \\
\hline South Africa & 0.363 & 0.317 & 0.251 \\
\hline Sweden & 0 & 0 & 0 \\
\hline Switzerland & 0 & 0 & 0 \\
\hline
\end{tabular}

Table A.2: Estimated weights for Exchange Rate with the SCM 


\begin{tabular}{l|c|c|c}
\hline \hline Country & \multicolumn{1}{c}{ Baseline } & \multicolumn{1}{c}{ Level } & Outcome \\
\hline Austria & 0 & 0 & 0 \\
Belgium & 0 & 0 & 0 \\
Brazil & 0 & 0.334 & 0 \\
Chile & 0 & 0 & 0.006 \\
China, P.R.: Mainland & 0 & 0 & 0 \\
Colombia & 0.177 & 0.01 & 0.161 \\
Czech Republic & 0 & 0 & 0 \\
Denmark & 0 & 0 & 0 \\
Egypt & 0 & 0 & 0 \\
Finland & 0 & 0 & 0 \\
France & 0 & 0 & 0 \\
Germany & 0 & 0 & 0 \\
Hungary & 0 & 0 & 0 \\
Iceland & 0.134 & 0.071 & 0.137 \\
India & 0 & 0.234 & 0 \\
Ireland & 0.169 & 0 & 0.165 \\
Israel & 0 & 0 & 0 \\
Italy & 0 & 0 & 0 \\
Korea, Republic of & 0 & 0 & 0 \\
Luxembourg & 0.037 & 0.125 & 0.038 \\
Malaysia & 0 & 0 & 0 \\
Mexico & 0 & 0 & 0 \\
Netherlands & 0 & 0 & 0 \\
Norway & 0 & 0 & 0 \\
Peru & 0.01 & 0 & 0 \\
Philippines & 0.216 & 0 & 0.201 \\
Poland & 0 & 0 & 0 \\
Portugal & 0 & 0 & 0 \\
Russian Federation & 0 & 0 & 0.034 \\
Singapore & 0 & 0 & 0 \\
South Africa & 0.258 & 0.225 & 0.257 \\
Sweden & 0 & 0 & 0 \\
Switzerland & 0 & 0 \\
\hline & & & \\
\hline
\end{tabular}

Table A.3: Estimated weights for Domestic Credit with the SCM 


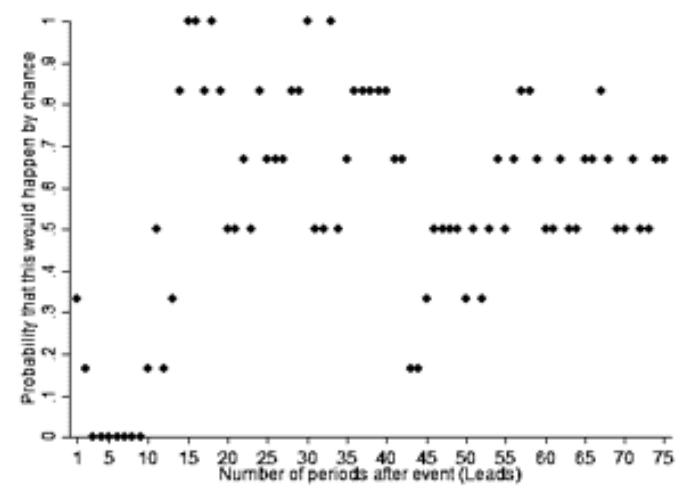

(a) Baseline

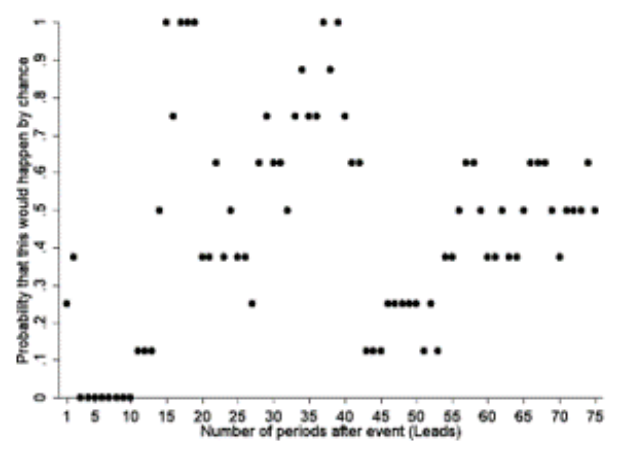

(b) Level

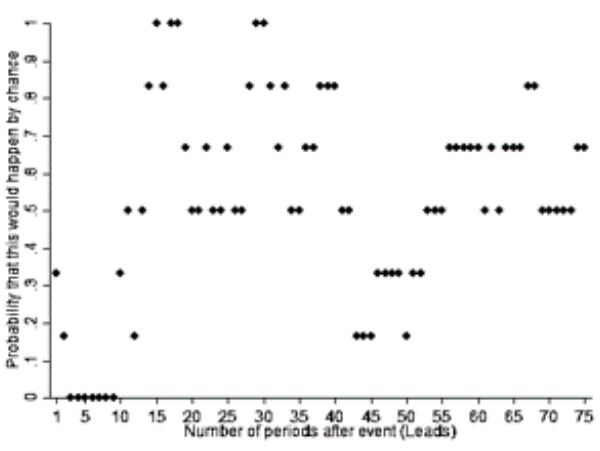

(c) Outcome

Figure A.8: p-values estimated for each period in CPI estimations, for each specification. Notes: the p-value is calculated as the proportion of placebo units who have not yield an effect as large as the treated has. 


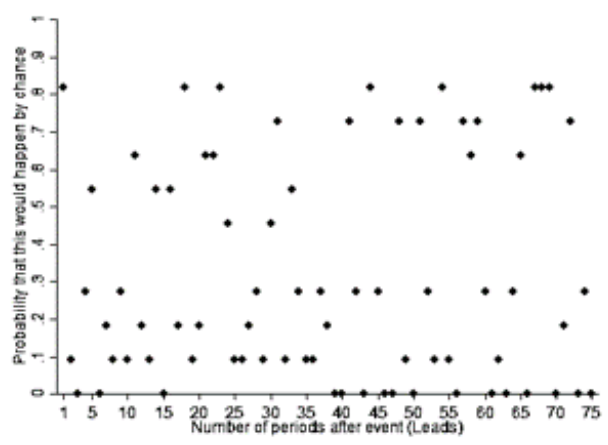

(a) Baseline

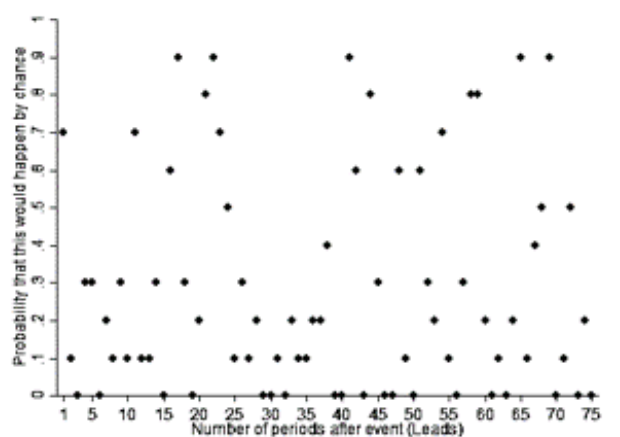

(b) Level

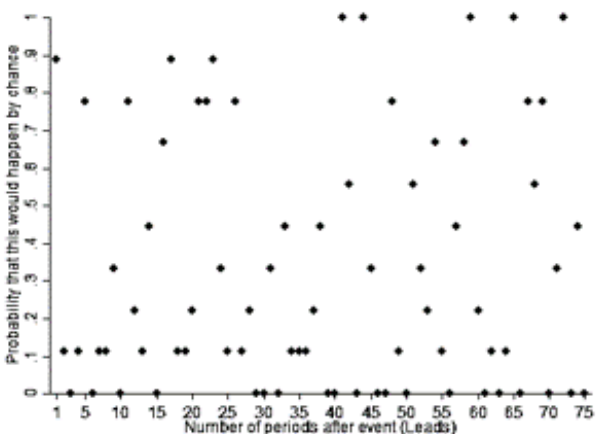

(c) Outcome

Figure A.9: p-values estimated for each period in exchange rate estimations, for each specification. Notes: the p-value is calculated as the proportion of placebo units who have not yield an effect as large as the treated has. 


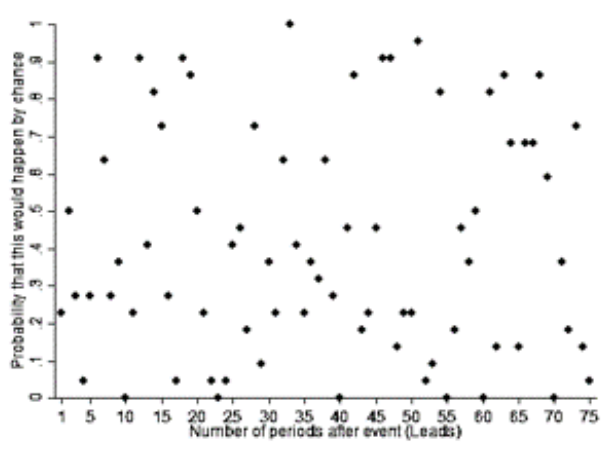

(a) Baseline

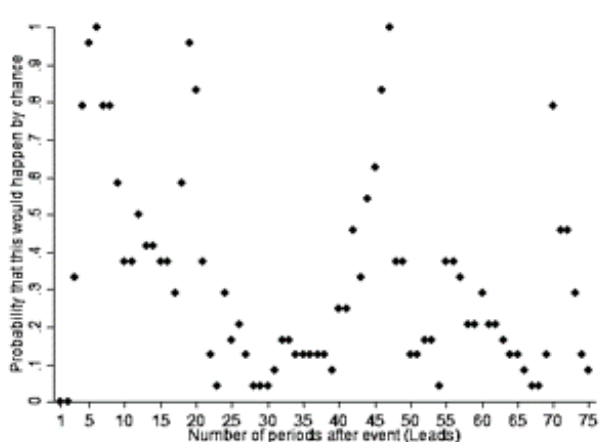

(b) Level

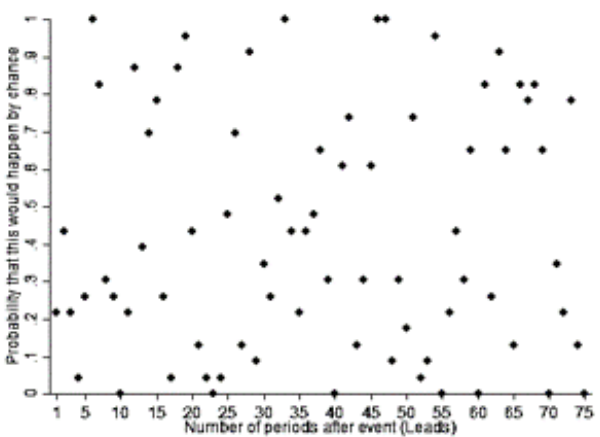

(c) Outcome

Figure A.10: p-values estimated for each period in credit estimations, for each specification. Notes: the p-value is calculated as the proportion of placebo units who have not yield an effect as large as the treated has.

\begin{tabular}{|c|c|c|c|c|}
\hline & & Baseline & Level & Outcome \\
\hline \multirow{2}{*}{ CPI } & $R^{2}$ & 0.509 & 0.514 & 0.809 \\
\hline & Joint p-value & 0.500 & 0.667 & 0.500 \\
\hline \multirow{2}{*}{ Exchange Rate } & $R^{2}$ & 0.744 & 0.744 & 0.770 \\
\hline & Joint p-value & 0.182 & 0.100 & 0.111 \\
\hline \multirow{2}{*}{ Domestic Credit } & $R^{2}$ & 0.810 & 0.896 & 0.809 \\
\hline & Joint p-value & 0.273 & 0.292 & 0.217 \\
\hline
\end{tabular}

Table A.4: Synthetic Control's analogous $R^{2}$ and joint p-values 


\begin{tabular}{ll}
\hline \hline CPI & 0.144 \\
Exchange Rate & 0.116 \\
Domestic Credit & 0.134 \\
\hline Joint & 0.023 \\
\hline
\end{tabular}

Table A.5: ArCo p-values. Notes: p-values are calculated by the 'ArCo' R package

\begin{tabular}{lccc}
\hline \hline & Lower-bound & Average Effect & Upper-bound \\
\hline Exchange & -0.00276 & 0.008561 & 0.019884 \\
CPI & -0.00722 & -0.00196 & 0.003297 \\
Credit & -0.11588 & -0.06587 & -0.01585 \\
\hline
\end{tabular}

Table A.6: Estimated average effect and Interval Confidence for ArCo

\section{A.4}

\section{ArCo Estimates}

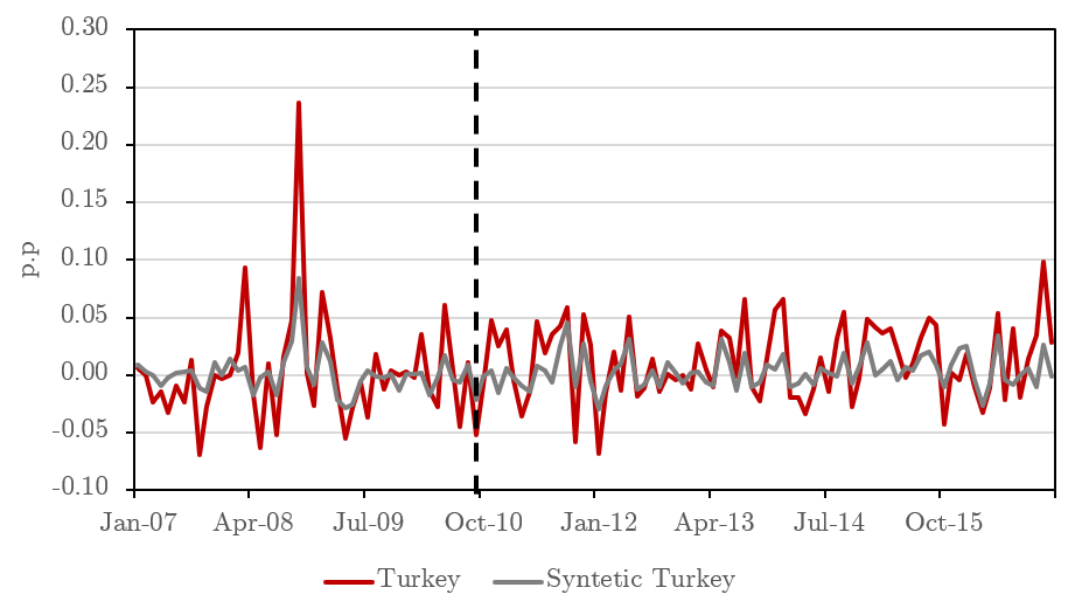

Figure A.11: ArCo raw estimation for Exchange Rate (log-difference) 


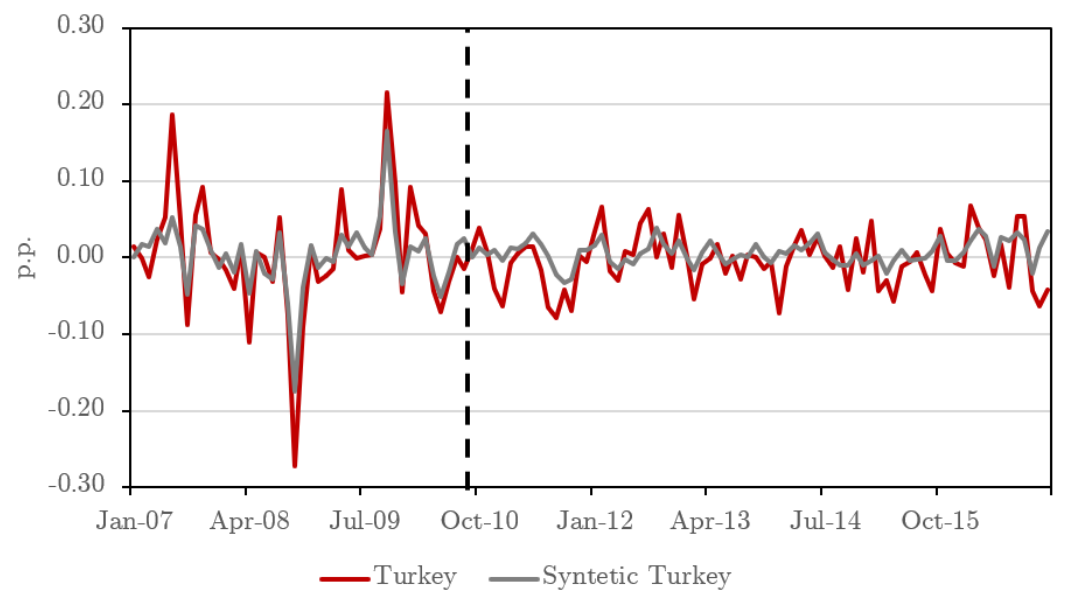

Figure A.12: ArCo raw estimations for Credit (first difference of growth rate)

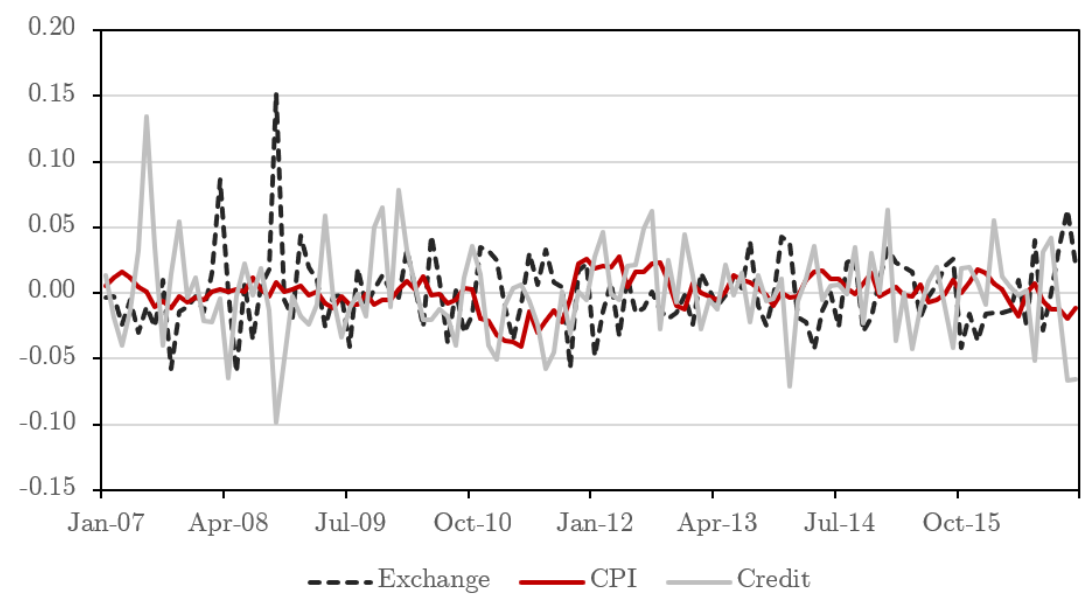

Figure A.13: ArCo residuals 


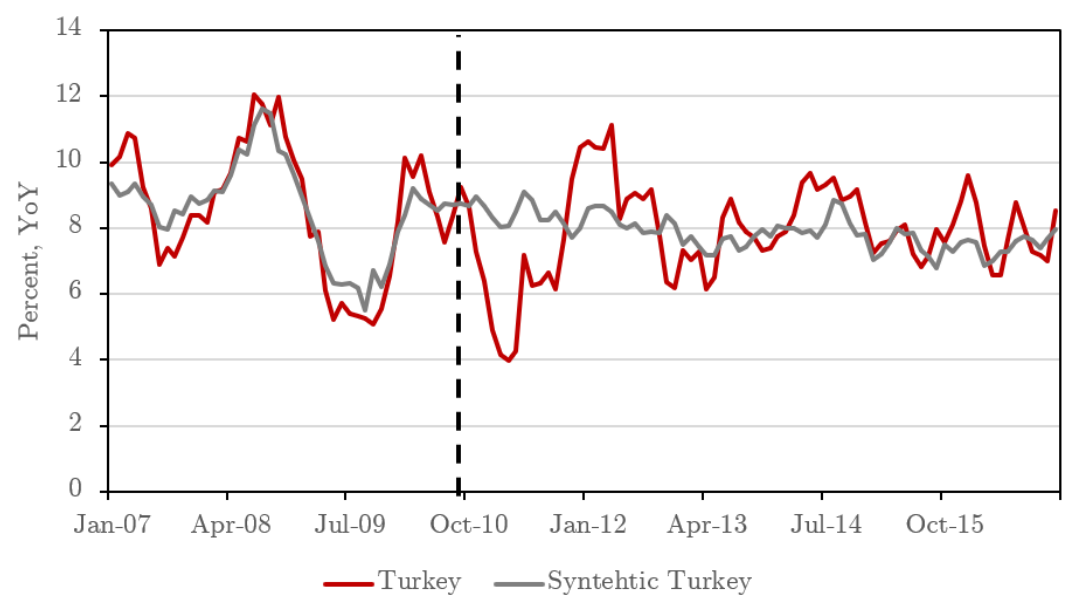

Figure A.14: ArCo for CPI with alternative data

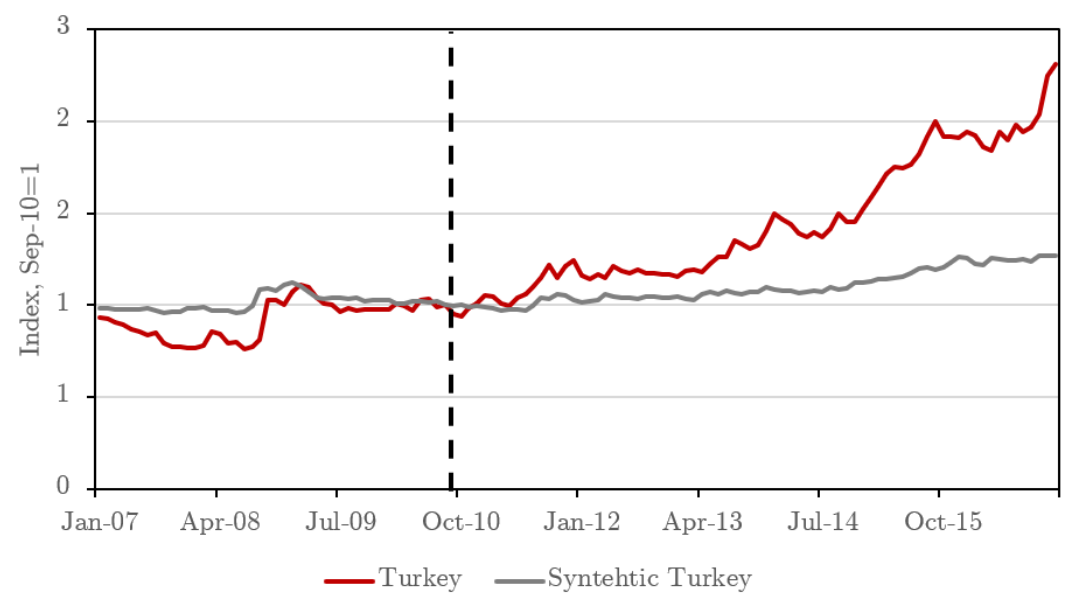

Figure A.15: ArCo for exchange rate with alternative data

\begin{tabular}{ll}
\hline \hline CPI & 0.874 \\
Exchange Rate & 0.144 \\
Domestic Credit & 0.001 \\
\hline Joint & 0.001 \\
\hline
\end{tabular}

Table A.7: ArCo p-values for alternative credit data. Notes: p-values are calculated by the 'ArCo' $\mathrm{R}$ package

\begin{tabular}{lccc}
\hline \hline & Lower-bound & Average Effect & Upper-bound \\
\hline Exchange & -0.00298 & 0.008716 & 0.020414 \\
CPI & -0.00449 & -0.00034 & 0.003817 \\
Credit & -0.05013 & -0.03959 & -0.02906 \\
\hline
\end{tabular}

Table A.8: Estimated average effect and Interval Confidence for ArCo with alternative credit data 